\title{
Quantifying the transport of subcloud layer reactants by shallow cumulus clouds over the Amazon
}

\author{
H. G. Ouwersloot, ${ }^{1,2}$ J. Vilà-Guerau de Arellano, ${ }^{1}$ B. J. H. van Stratum, ${ }^{3}$ \\ M. C. Krol, ${ }^{1}$ and J. Lelieveld ${ }^{2}$ \\ Received 26 June 2013; revised 15 October 2013; accepted 16 October 2013; published 11 December 2013.
}

[1] We investigate the vertical transport of atmospheric chemical reactants from the subcloud layer to the cumulus cloud layer driven by shallow convection over the Amazon during the dry season. The dynamical and chemical assumptions needed for mesoscale and global chemistry transport model parametrizations are systematically analyzed using a Large Eddy Simulation model. We quantify the mass flux transport contribution to the temporal evolution of reactants. Isoprene, a key atmospheric compound over the tropical rain forest, decreases by $8.5 \% \mathrm{~h}^{-1}$ on average and $15 \% \mathrm{~h}^{-1}$ at maximum due to mass-flux-induced removal. We apply mass flux parametrizations for the transport of chemical reactants and obtain satisfactory agreement with numerically resolved transport, except for some reactants like $\mathrm{O}_{3}, \mathrm{NO}$, and $\mathrm{NO}_{2}$. The latter is caused by the local partitioning of reactants, influenced by UV radiation extinction by clouds and small-scale variability of ambient atmospheric compounds. By considering the longer-lived $\mathrm{NO}_{x}\left(\mathrm{NO}+\mathrm{NO}_{2}\right)$, the transport is well represented by the parametrization. Finally, by considering heterogeneous surface exchange conditions, it is demonstrated that the parametrizations are sensitive to boundary conditions due to changes in the boundary layer dynamics.

Citation: Ouwersloot, H. G., J. Vilà-Guerau de Arellano, B. J. H. van Stratum, M. C. Krol, and J. Lelieveld (2013), Quantifying the transport of subcloud layer reactants by shallow cumulus clouds over the Amazon, J. Geophys. Res. Atmos., 118, 13,041-13,059, doi:10.1002/2013JD020431.

\section{Introduction}

[2] The Amazon rain forest plays an important role in regulating the regional and global atmospheric composition [Zimmerman et al., 1988; Karl et al., 2007], particularly due to high biogenic volatile organic compound (BVOC) emissions. However, to accurately represent and predict the atmospheric chemistry over this ecosystem, the role of dynamics [Butler et al., 2008; Ganzeveld et al., 2008] and chemical processes [e.g., Lelieveld et al., 2008] need to be better understood. Since atmospheric chemistry depends on the surface exchange of biogenic compounds, the reactivity is controlled by processes that occur in the atmospheric boundary layer (ABL). The ABL dynamics have multiple effects on atmospheric chemistry. Here we investigate the transport by shallow cumulus ( $\mathrm{SCu}$ ) convection and its implications for the subcloud layer chemistry, using a Large Eddy Simulation (LES) model. The focus is primarily on the subcloud atmospheric properties since the conditions there

\footnotetext{
${ }^{1}$ Meteorology and Air Quality, Wageningen University and Research Centre, Wageningen, Netherlands.

${ }^{2}$ Max Planck Institute for Chemistry, Mainz, Germany.

${ }^{3}$ Max Planck Institute for Meteorology, International Max Planck Research School on Earth System Modelling, Hamburg, Germany.

Corresponding author: H. G. Ouwersloot, Meteorology and Air Quality, Wageningen University and Research Centre, Wageningen, Netherlands. (huug.ouwersloot@wur.nl)

(C)2013. American Geophysical Union. All Rights Reserved. 2169-897X/13/10.1002/2013JD020431
}

are directly linked to the Earth's surface. Therefore, knowledge of the processes that occur in the subcloud region is important for interpreting data. This study quantifies the fluxes from the subcloud to the cloud layer and their impact on the reactant mixing ratios. We aim to contribute to parametrizations that represent this transport in chemistry transport and climate models. This is of importance considering that $\mathrm{SCu}$ cloud processes occur at scales that are not resolved in such models [Kim et al., 2012]. We also analyze the effects of heterogeneous surface forcings.

[3] In the Amazon region, daytime shallow cumulus (fair weather) clouds are present during approximately $50 \%$ of the time in the period June-August [Hahn and Warren, 2007]. Shallow cumulus clouds affect the atmospheric dynamics and chemistry in multiple ways. Next to regulating the growth of the convectively mixed subcloud layer, clouds affect radiation [Madronich, 1987], thereby changing the chemical reaction rates and surface heat fluxes. Previous LES studies have shown that the attenuation of UV radiation has a profound impact on the instantaneous below-cloud chemistry, resulting in changes up to $10 \%$ (for $\mathrm{NO}_{2}$ ) in the spatial averaged subcloud layer mixing ratios of reactants [Vilà-Guerau de Arellano et al., 2005; Kim et al., 2012]. Related to the ABL dynamics, the SCu clouds transport atmospheric constituents from the mixed layer to the free troposphere (FT), enhance entrainment of free tropospheric air into the boundary layer and can trigger deep convection [Zhang and Klein, 2010]. The subcloud layer height, below which chemical reactants are well mixed, is 
lowered by air masses that are transported by the thermals from the subcloud layer into the cloud layer, the so-called mass flux [Siebesma and Cuijpers, 1995]. This height influences the mixing ratios of chemical species in the subcloud layer, as demonstrated with conceptual mixed-layer models [van Stratum et al., 2012; Ouwersloot et al., 2012]. The feedbacks between mixed-layer height, mass flux, and entrainment rate is explored in more detail by B. J. H. van Stratum et al. (Sub-cloud layer feedbacks driven by the mass flux of shallow cumulus convection over land, submitted to Journal of the Atmospheric Sciences, 2013). SCu clouds also give rise to large-scale structures in the subcloud layer [ Kim et al., 2012] similar to those induced by surface heterogeneity [Patton et al., 2005] and affecting atmospheric chemistry [Ouwersloot et al., 2011]. An additional effect of clouds on atmospheric chemistry is related to chemical reactions within the cloud droplets. This aqueous phase chemistry [e.g., Sorooshian et al., 2007; Roelofs and Kamphuis, 2009; Shrivastava et al., 2013] is not considered here as it mainly affects the atmospheric composition in the cloud layer and not the temporal evolution of mixing ratios in the subcloud layer.

[4] In this study we investigate the impact of mass flux transport on the mixing ratios of atmospheric reactants. We address Amazonian conditions, inspired by the Tropical Forest and Fire Emission Experiment (TROFFEE) [Karl et al., 2007; Vilà-Guerau de Arellano et al., 2011]. We quantify the influence of the mass flux on the budget of chemical species using two different expressions. One considers the additional effect of the mass flux compared to boundary layer growth, and the other considers the additional effect of the mass flux compared to entrainment. These two approaches are complementary and can be applied for different analyses, as will be discussed in detail. Furthermore, we discuss how the impact of mass flux depends on the spatial distribution of the chemical species as a first step toward a parametrization in large-scale models. This is complemented by an evaluation of the impact of the altered UV radiation below clouds on the transport by $\mathrm{SCu}$ convection. The analysis is completed by discussing how heterogeneous surfaces can modify the mass flux.

[5] The next section introduces the theory of mass flux and its impact on the chemistry budget. This is followed by a description of the LES model and the numerical experiments. Then, the dynamical effects of the mass flux are compared to values reported in literature to affirm if they are consistent. Next, the spatial distributions of dynamical variables and reactant mixing ratios and their influence on cloud transport are discussed, and the mass flux contribution to the mixing ratio budgets is quantified. Subsequently, we investigate representative expressions for the mass flux transport contributions to the budgets, showing differences between various types of chemical species. Finally, we demonstrate that surface heterogeneity influences the results.

\section{Methodology}

\subsection{Mass Flux}

[6] Here we define the framework that will be used to develop and test a parametrization for the mass flux transport of atmospheric constituents, including specific humidity. In section 2.1.1, the definitions for the mass flux are presented.
Subsequently, the impact of the cloud-base mass flux on the boundary layer growth and scalar evolutions are presented in section 2.1.2. Finally, the analysis of the mass flux transport from the LES data and its parametrization are discussed in section 2.1.3. The parametrizations are based on numerical data sampled from the large eddy simulation.

\subsubsection{Mass Flux Definition}

[7] In convectively mixed ABLs that are topped by $\mathrm{SCu}$ clouds, transport of air occurs from the (well-mixed) subcloud layer to the free atmosphere by thermals that become active cumulus clouds above the lifting condensation level. To identify transport by these thermals, we are limited to analyzing the active clouds that are rooted into them [LeMone and Pennell, 1976], since the organized transport below the clouds cannot be discriminated from the upward moving air parcels that are caused by entrainment related turbulence. The transport, quantified as the kinematic convective mass flux (hereafter referred to as mass flux), $M$ [Siebesma and Cuijpers, 1995], depends on the vertical velocity in and the area fraction of the active clouds. These active clouds, which are positively buoyant [Stull, 1988], are referred to as the cloud cores [Heus and Jonker, 2008]. The corresponding mass flux is defined as

$$
M=a_{\mathrm{cc}}\left(w_{\mathrm{cc}}-\bar{w}\right),
$$

where $a_{\mathrm{cc}}$ is the (horizontal) area fraction, $a$, of the cloud cores, $\bar{w}$ is the Reynolds averaged vertical wind velocity, $w$, and $w_{\text {cc }}$ is the average $w$ sampled over the cloud cores. These properties are all height dependent. Note that the cloud core area fraction is not equal to the total cloud core cover, $c_{\mathrm{cc}}$, since that quantity is determined using vertically integrated values. The index $c$ is used for samples over all SCu clouds.

[8] Similar to Siebesma and Cuijpers [1995], the total vertical transport of an arbitrary scalar, $\phi$, is partitioned in advective and turbulent fluxes for clouded areas and the environmental air by

$$
\begin{aligned}
\overline{w^{\prime} \phi^{\prime}}= & a_{\mathrm{cc}}\left(\left(w_{\mathrm{cc}}-\bar{w}\right)\left(\phi_{\mathrm{cc}}-\bar{\phi}\right)+{\overline{w^{\prime} \phi^{\prime}}}^{\mathrm{cc}}\right)+ \\
& \left(1-a_{\mathrm{cc}}\right)\left(\left(w_{\mathrm{env}}-\bar{w}\right)\left(\phi_{\mathrm{env}}-\bar{\phi}\right)+{\overline{w^{\prime} \phi^{\prime}}}^{\mathrm{env}}\right),
\end{aligned}
$$

where the subscripts cc and env indicate cloud core and environmental averages, respectively. The cloud and environment indexed overlines $\left({ }^{\mathrm{cc}}\right.$ and $\left.{ }^{\mathrm{env}}\right)$ denote that the considered fluctuations are relative to the cloud and environment averages. Within the two pairs of brackets that are linked to the area fraction of a sampling criterion (i.e., cloud core or environment) in equation (2), the first term is related to the corresponding organized transport and the second term quantifies the corresponding turbulent flux. As will be corroborated in this study, within the cloud cores the organized transport dominates the total flux [Siebesma and Cuijpers, 1995]. Further, since $\bar{\phi}=a_{\mathrm{cc}} \phi_{\mathrm{cc}}+\left(1-a_{\mathrm{cc}}\right) \phi_{\mathrm{env}}$,

$$
\left(1-a_{\mathrm{cc}}\right)\left(w_{\mathrm{env}}-\bar{w}\right)\left(\phi_{\mathrm{env}}-\bar{\phi}\right)=\frac{a_{\mathrm{cc}}}{1-a_{\mathrm{cc}}} a_{\mathrm{cc}}\left(w_{\mathrm{cc}}-\bar{w}\right)\left(\phi_{\mathrm{cc}}-\bar{\phi}\right),
$$

so the organized transport in the environment is only $\frac{a_{\mathrm{cc}}}{1-a_{\mathrm{cc}}}$ times the organized transport in the cloud cores. Note that the average vertical wind velocity in the environment is dependent on the average in the cloud cores by $w_{\mathrm{env}}-\bar{w}=$ $-\frac{a_{\mathrm{cc}}}{1-a_{\mathrm{cc}}}\left(w_{\mathrm{cc}}-\bar{w}\right)$. In the cases under study, the factor $\frac{a_{\mathrm{cc}}}{1-a_{\mathrm{cc}}}$ is small (4.7\% at maximum) and the organized transport 
in the environment is negligible. In the $\mathrm{SCu}$ cloud layer, the mass flux is much larger than the turbulent transport in the environment and dominates the total vertical transport. Therefore,

$$
\overline{w^{\prime} \phi^{\prime}} \approx M\left(\phi_{\mathrm{cc}}-\bar{\phi}\right)
$$

The validity of this approximation was already demonstrated for potential temperature, specific humidity [e.g., Siebesma and Cuijpers, 1995], and chemical species [Vilà-Guerau de Arellano et al., 2005] and will be confirmed by the results presented in section 3. In the remainder of this paper, we investigate this organized transport in the cloud cores.

[9] Even though the decomposition into cloud core areas and environment is based on dynamical arguments, the choice for two areas is arbitrary. One could think of different divisions, e.g., cloud cores, remaining clouds and environment [Siebesma and Cuijpers, 1995; Heus and Jonker, 2008], as will be discussed in section 3.6.

\subsubsection{Impact of Mass Flux}

[10] Mixed layer theory [Lilly, 1968] is used to quantify the impact of the cloud base mass flux on the subcloud layer height. Since this work expands on previous studies, a zeroth-order mixed layer model is used. Although a firstorder approach could be more suitable in specific situations, this model is shown to properly reproduce the evolution of the boundary layer for a wide range of atmospheric conditions [e.g., Neggers et al., 2006; B. J. H. van Stratum et al., submitted manuscript, 2013]. The evolution of the subcloud layer (or mixed layer) height, $h$, is expressed [Neggers et al., 2006] as

$$
\frac{\partial h}{\partial t}=w_{e}+\bar{w}(h)-M,
$$

where $w_{e}$ is the entrainment velocity and $\bar{w}(h)$ is the largescale vertical velocity at height $h$. Here, $M$ is shorthand for the mass flux that escapes the subcloud layer, $M(h)$. From here on we consider that $\bar{w}(h)=0$ in our numerical setup. According to a budget analysis (B. J. H. van Stratum et al., submitted manuscript, 2013), the mixing ratio of an arbitrary atmospheric compound, $\phi$, with chemical production $P$ and $\operatorname{loss} L$ is governed by

$$
\frac{\mathrm{d}\langle\phi\rangle}{\mathrm{d} t}=\frac{\overline{w^{\prime} \phi^{\prime}}{ }_{0}+w_{e} \Delta \phi-M\left(\phi_{\mathrm{cc}}-\langle\phi\rangle\right)}{h}+P-L,
$$

where $\langle\phi\rangle$ is the mixed layer averaged value and $\Delta \phi$ is the concentration jump at the top of the mixed layer. The latter is equal to $\bar{\phi}\left(h^{+}\right)-\langle\phi\rangle$, where $\bar{\phi}\left(h^{+}\right)$is the average value of $\phi$ just above the subcloud layer. $\overline{w^{\prime} \phi^{\prime}}$ is the turbulent flux at the surface. Equation (5) shows that, in contrast to previously stated [Neggers et al., 2006], the mass flux can directly change mixed layer averaged properties if $\phi_{\mathrm{cc}}$ differs from $\langle\phi\rangle$. Next to the enhanced entrainment (B. J. H. van Stratum et al., submitted manuscript, 2013), this contributes to the reduction of mixing ratios of emitted passive tracers in the subcloud layer that was found by Kim et al. [2012].

[11] Even if the growth of the mixed layer is negligible, the entrainment and the mass flux may still exchange air between the subcloud and the cloud layer. With constant height, all air mass that leaves the subcloud layer with property $\phi_{\mathrm{cc}}$ returns with property $\bar{\phi}\left(h^{+}\right)$due to the compensating entrainment. This effect can be recognized more easily by rearranging equation (5). Using equation (4) to split the entrainment velocity in mixed layer growth and compensation for the loss of mixed layer air by the mass flux, yields

$$
\frac{\mathrm{d}\langle\phi\rangle}{\mathrm{d} t}=\frac{\overline{w^{\prime} \phi^{\prime}}{ }_{0}+\frac{\mathrm{d} h}{\mathrm{~d} t} \Delta \phi-M\left(\phi_{\mathrm{cc}}-\bar{\phi}\left(h^{+}\right)\right)}{h}+P-L .
$$

This shows that, next to surface exchange and chemical production and loss, two additional contributions to the mixing ratio budget are as follows: (i) the mixing of subcloud and cloud layer air due to the mixed layer growth (second term in the fraction) and (ii) the aforementioned circulation of air at the top of the subcloud layer with a flow rate $M$ (third term in the fraction). While equation (5) can be used to analyze the contributions of different dynamical processes (such as entrainment and venting of air by mass flux), equation (6) is more straightforward when evaluating the mixing ratio budget based on data from observations or numerical experiments with turbulence resolving models (e.g., LES). To distinguish between these two budgets, equation (5) is referred to as the "venting budget," and equation (6) is referred to as the "pumping budget" in section 3. Using LES data, the mixed layer height evolution and the mass flux can be quantified directly. Additionally, according to equation (3), the mass flux contribution in equation (6) can be compared directly to the total vertical scalar transport in the cloud layer. Therefore, we will mainly focus on the pumping budget equation in our analysis.

\subsubsection{Mass Flux Parametrization}

[12] The cloud-base height, $z_{b}$, at which the mass flux is quantified, is under the investigated conditions actually higher than the subcloud layer height. The difference between these two heights determines the depth of the transition layer, which is a key length scale in the parametrization of the standard deviations of scalars at the mixed layer top [Neggers et al., 2006, 2007; B. J. H. van Stratum et al., submitted manuscript, 2013]. Even though the mass flux out of the mixed layer, $M(h)$, is under investigation, $M\left(z_{b}\right)$ is a good proxy since all the air that escapes the subcloud layer is transported by the $\mathrm{SCu}$ convection. To determine the mass flux in the dry thermals at $h$ instead, one would have to separate the contributions of organized transport and turbulent motions to the total vertical transport of air at this height. Then $\phi_{\mathrm{cc}}$ could be determined by sampling in the upward organized transport. However, this was computationally not attainable in this study. Here the cloud base height is diagnosed as the height with maximum $a_{\mathrm{cc}}$ [Neggers et al., 2007] and the subcloud layer height as the inversion height, $z_{\mathrm{i}}$, determined by the vertical profile of the virtual potential temperature, $\theta_{v}$. The inversion height is calculated using the threshold gradient method [Ouwersloot et al., 2011], diagnosing $z_{i}$ as the lowest level where $\frac{\mathrm{d} \theta_{v}}{\mathrm{~d} z}>\left(0.5 \max \frac{\mathrm{d} \theta_{v}}{\mathrm{~d} z}\right)$. An illustration of the structure of the SCu cloud topped mixed layer is presented in Figure 1. The symbol $e$ indicates entrainment and $\gamma_{\phi}$ is the vertical gradient of $\phi$ in the cloud layer (free troposphere) for cloudy (clear sky) conditions.

[13] For models that do not (fully) resolve the cloud processes, the values for $w_{\mathrm{cc}}, a_{\mathrm{cc}}$, and $\phi_{\mathrm{cc}}$ have to be parametrized. Building on Neggers et al. [2006], B. J. H. van Stratum et al. (submitted manuscript, 2013) state, based on LES analyses for different cases with $\mathrm{SCu}$ convection over land, that $w_{\mathrm{cc}}$ scales with the Deardorff convective velocity scale [Stull, 1988], $w_{*}$, as

$$
w_{\mathrm{cc}}=\lambda w_{*}
$$




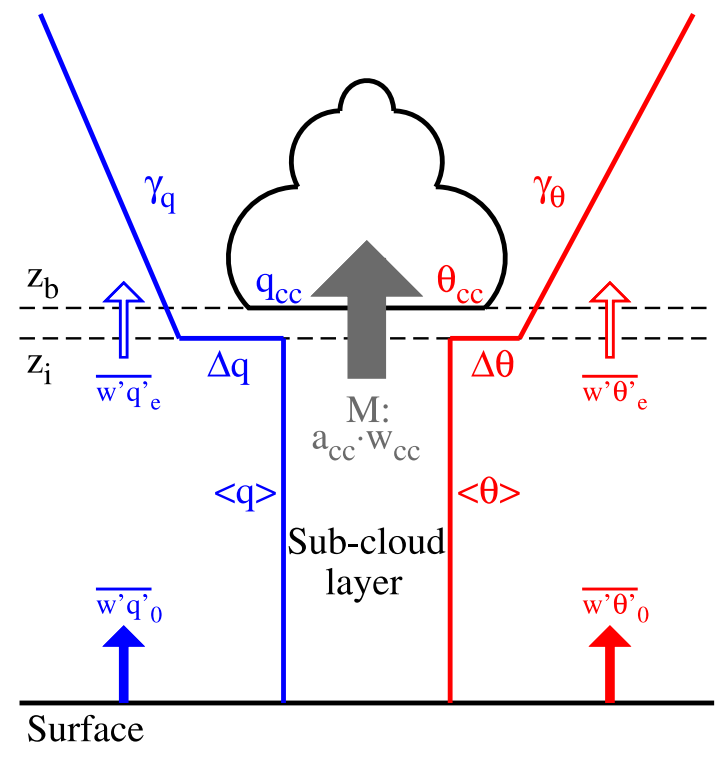

Figure 1. Schematic overview of the vertical structure of the convectively mixed layer topped by shallow cumulus clouds. The variables are defined in section 2.1.

where $\lambda=0.84$. The cloud core value of $q$ is prescribed by

$$
q_{\mathrm{cc}}-<q>=\zeta \sigma_{q, h},
$$

in which $\zeta=0.51$ and $\sigma_{q, h}$ is the standard deviation of $q$ at the top of the subcloud layer. These parametrizations for $w_{\mathrm{cc}}$ and $q_{\mathrm{cc}}$ are evaluated in section 3. Here we additionally study the parametrizations for $\phi_{\mathrm{cc}}$ considering scalars other than $q$. Since equations (5) and (6) express the mixed layer budget of $\langle\phi\rangle$, we analyze the parametrizations for $\phi_{\mathrm{cc}}-\langle\phi\rangle$ and $\phi_{\mathrm{cc}}-\bar{\phi}\left(h^{+}\right)$. To prevent the sampling of subcloud layer air when calculating the value for $\phi$ at the bottom of the cloud layer, $\bar{\phi}\left(z_{b}\right)$ is used as a proxy for $\bar{\phi}\left(h^{+}\right)$. This value is only evaluated if $c_{\mathrm{cc}} \geq 0.05$, because then enough active clouds are present to accurately determine $z_{b}$.

\subsection{LES Model}

[14] The LES model that is employed is based on version 3.2 of the Dutch Atmospheric Large Eddy Simulation (DALES) model [Heus et al., 2010], extended with a chemistry module [Vilà-Guerau de Arellano et al., 2005] and expanded to enable studies of ABLs that are characterized by heterogeneous boundary conditions at the surface [Ouwersloot et al., 2011]. This LES code has been introduced by Nieuwstadt and Brost [1986]. Further developments and improvements were made [e.g., Cuijpers and Duynkerke, 1993; Dosio et al., 2003] prior to resulting in DALES 3.2.

[15] DALES solves dynamical and chemical processes in the ABL explicitly on a computational grid resolution (typically $100 \mathrm{~m}$ or less) that is much finer than that of mesoscale and global models, but still requires parametrization of the smaller scale turbulence. For this parametrization, the filtered Navier-Stokes equations are applied, using the one-and-a-half-order closure assumption [Deardorff, 1973], in combination with the Boussinesq approximation [Heus et al., 2010]. The corresponding filter size is generally set equal to the grid resolution, which is chosen such that less than $10 \%$ of the total turbulent energy is parametrized. In the horizontal directions, the domain is constrained by periodic boundary conditions. Related to the interaction of clouds with UV radiation, the photolysis rates are multiplied with separate factors below and above the clouds in each vertical column of the computational grid (only taking into account the one-dimensional effects). This multiplication is described by Vilà-Guerau de Arellano et al. [2005]. The second-order effect of adjusted surface heat and moisture fluxes due to the altered radiation is not applied.

\subsection{Numerical Experiments}

[16] The $256 \times 256 \times 300$ grid applied in the LES experiments spans $12,800 \mathrm{~m} \times 12,800 \mathrm{~m} \times 6000 \mathrm{~m}$ with a resolution of $50 \mathrm{~m} \times 50 \mathrm{~m} \times 20 \mathrm{~m}$. Although this resolution suffices to resolve most of the turbulent kinetic energy, for future studies it is recommended to repeat the presented analysis with a finer resolution if allowed by the computational resources. The numerical experiments start at 5 local time (LT) and are run for $11.5 \mathrm{~h}$, using a time step of $1 \mathrm{~s}$. Larger time steps lead to instabilities in the chemical solver. These temporal and spatial resolutions suffice to resolve the most relevant processes for both the atmospheric dynamics and chemistry. Statistics are calculated and stored every minute.

[17] The numerical experiments are aimed at investigating the role of shallow cumulus convection for Amazonian subcloud layer reactants. The evaluated case is based on the TROFFEE campaign [Karl et al., 2007; Vilà-Guerau de Arellano et al., 2011] that took place 14-29 September 2004 (dry season) in the Amazonian rain forest. The dynamical and chemical surface conditions are set equal to those prescribed by Vilà-Guerau de Arellano et al. [2011]. However, the upper atmospheric conditions were less wellknown. Therefore, we prescribe initial vertical profiles based on the previous study but slightly changed. While doing so, we paid attention to reproduce a situation in which $\mathrm{SCu}$ convection occurred that did not evolve into deep convection and to keep the profiles realistic and representative for Central Amazonia. We consider local free convection (i.e., no mean horizontal wind velocity).

[18] The initial boundary layer height was set to $200 \mathrm{~m}$. Below this height, the initial potential temperature, $\theta$, is $300 \mathrm{~K}$ and the initial specific humidity, $q$, is $16 \times 10^{-3} \mathrm{~kg} \mathrm{~kg}^{-1}$. The respective jumps in these values from the mixed layer to the free troposphere are $1 \mathrm{~K}$ and $-3 \times 10^{-3} \mathrm{~kg} \mathrm{~kg}^{-1}$. Above this height, there are two regimes in which $\theta$ changes with a different vertical gradient each, as is commonly observed [e.g., Brown et al., 2002]. It increases by $3 \times 10^{-3} \mathrm{~K} \mathrm{~m}^{-1}$ up to $4 \mathrm{~km}$ altitude and $6 \times 10^{-3} \mathrm{~K} \mathrm{~m}^{-1}$ above $4 \mathrm{~km}$. The specific humidity drops by $-3 \times 10^{-6} \mathrm{~kg} \mathrm{~kg}^{-1} \mathrm{~m}^{-1}$ until it is equal to 0 (at $\sim 4.5 \mathrm{~km}$ altitude). The surface kinematic heat flux is prescribed by

$$
\overline{w^{\prime} \theta^{\prime}}=0.19 \sin \left(\frac{\pi(t-8100)}{28,800}\right) \mathrm{Km} \mathrm{s}^{-1}
$$

between 0715 and $1515 \mathrm{LT}$ and 0 at any other time, where $t$ is the time in seconds since 5 LT. The surface kinematic moisture flux is

$$
\overline{w^{\prime} q^{\prime}}=0.13 \times 10^{-3} \sin \left(\frac{\pi(t-3600)}{37,800}\right) \mathrm{kg} \mathrm{kg}^{-1} \mathrm{~m} \mathrm{~s}^{-1}
$$

between 0600 and $1630 \mathrm{LT}$ and 0 at any other time. 
[19] When investigating the impact of surface heterogeneities on the transport by shallow cumulus convection, the surface is subdivided into four patches in one horizontal direction [Ouwersloot et al., 2011], resulting in a length scale of heterogeneity (the width of a forest and savannah patch combined) of $6.4 \mathrm{~km}$. The first and the third patches are characteristic for forest and the other two for savannah. In the forest areas, the sensible heat flux is lower and the latent heat flux is higher. In this study, the sum of sensible and latent heat fluxes is kept constant per patch. Additionally, the average sensible and latent heat fluxes over the entire domain are kept equal to the conditions with a homogeneous surface. Similar to Ouwersloot et al. [2011], the change in sensible and latent heat flux is set to a third of the sensible heat flux over the homogeneous surface. This results in an amplitude of $0.125(0.255) \mathrm{K} \mathrm{m} \mathrm{s}^{-1}$ in the kinematic heat flux for the forest (savannah) patches and an amplitude of $0.156(0.104) \times 10^{-3} \mathrm{~kg} \mathrm{~kg}^{-1} \mathrm{~m} \mathrm{~s}^{-1}$ in the kinematic moisture flux. The resulting sensible and latent heat fluxes correspond to a maximum Bowen ratio of 0.32 (0.99) for the forest (savannah) area, being representative for the dry season $[d a$ Rocha et al., 2009]. For homogeneous surface conditions, the maximum Bowen ratio during the day is 0.59 . Over a heterogeneous surface with this length scale and distribution of sensible and latent heat fluxes, coherent mesoscale circulations are induced that affect the distribution of scalars within the mixed layer as well as the evolution of the ABL height and mixed-layer averaged properties [e.g., Patton et al., 2005; Ouwersloot et al., 2011] facilitating cloud formation [van Heerwaarden et al., 2010]. The presence of these circulations and their impact on the boundary layer dynamics in cases with light ambient winds have been confirmed by observations [Doran et al., 1995].

[20] The chemical mechanism is based on the one proposed by Vilà-Guerau de Arellano et al. [2009], which contains the basic reactions for the $\mathrm{O}_{3}-\mathrm{NO}_{x}-\mathrm{VOC}-\mathrm{HO}_{x}$ mechanism that represents daytime chemistry over the Amazon rain forest. After some expansions [Vilà-Guerau de Arellano et al., 2011; Ouwersloot et al., 2011; van Stratum et al, 2012], the current mechanism was presented by Ouwersloot et al. [2012]. In this chemical scheme, 20 reactant species are included. Note that methyl vinyl ketone $(\mathrm{MVK})$ is here a lumped species with all first-generation oxidation products of isoprene $\left(\mathrm{C}_{5} \mathrm{H}_{8}\right)$. The chemical reactions and the expressions for the reaction rates are presented in Table 1. The mixing ratios of the reactants are first converted to concentrations (in molec $\mathrm{cm}^{-3}$ ) before applying the chemical production and loss and back again afterward. Apart from the 20 reactant species listed in this table, three passive tracers are considered: an emitted tracer (INERT), an inert species that is initially only present in the mixed layer (BLS), and an inert species that is initially only present in the free troposphere (FTS). For the latter two species there is no surface exchange. INERT and BLS/FTS are inspired on the classical "bottom-up" and "top-down" tracers [Wyngaard and Brost, 1984], respectively.

[21] For 11 tracers, the vertical profile is initialized to $0 \mathrm{ppb}$. The exceptions to this profile are as follows. The chemical species $\mathrm{H}_{2} \mathrm{O}$ is linked to and governed by $q . \mathrm{O}_{3}$, $\mathrm{CH}_{4}, \mathrm{MVK}, \mathrm{C}_{5} \mathrm{H}_{8}, \mathrm{CO}, \mathrm{O}_{2}$, and $\mathrm{N}_{2}$ are initialized with respectively $10,1724,1.3,2,124,0.2 \times 10^{9}$, and $0.8 \times 10^{9}$ $\mathrm{ppb}$ at all heights. $\mathrm{NO}_{2}$ is $1 \mathrm{ppb}$ in the mixed layer and
$0.5 \mathrm{ppb}$ aloft. Tracer BLS (FTS) is initialized only in (above) the mixed layer with $1 \mathrm{ppb}$. Since the sum of the initial BLS and FTS mixing ratios is $1 \mathrm{ppb}$ everywhere, and they do not experience surface exchange or chemical transformations, the tracers are complementary.

[22] The surface exchange of the atmospheric tracers is

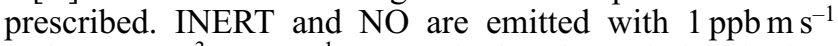
and $0.5 \times 10^{-3} \mathrm{ppb} \mathrm{m} \mathrm{s}^{-1}$, respectively. The emission for isoprene, $E_{\mathrm{Iso}}$, is based on observations [Karl et al., 2007] and prescribed as

$$
E_{\text {Iso }}=0.65 \exp \left(-\frac{\left(\frac{t-24705}{7999}\right)^{2}}{2}\right) \mathrm{ppb} \mathrm{m} \mathrm{s}^{-1}
$$

where again $t$ is the time in seconds since 5 LT. When heterogeneous surface conditions are considered, the isoprene emission is higher (lower) in the forest (savannah) patches and the value 0.65 is replaced by $1.0(0.3)$. The UV radiation is calculated as a function of time by determining the solar zenith angle at the geographical location under study $\left(2.612^{\circ} \mathrm{S}, 60.91^{\circ} \mathrm{W}\right)$.

\section{Results}

\subsection{Dynamics}

[23] The temporal evolution of liquid water potential temperature, $\theta_{l}$, and specific humidity, $q$, is presented in Figure 2 for the duration of the numerical experiment. Both variables are horizontally averaged. Additionally, the evolutions of the diagnosed mixed layer height and cloud base height are depicted. Here $z_{b}$ is only determined if $c_{\mathrm{cc}}>0.1 \%$. Note that the latent heat flux is 0 before 0600 LT, and the sensible heat flux is 0 before 0715 LT. After the breaking of the morning capping inversion, the mixed layer begins to deepen near 0800 LT. The first active clouds appear around 1030 LT and start to increase in number and depth near 1130 LT (see Figure 3a). All active clouds have dissipated by 1530 LT, $15 \mathrm{~min}$ after the sensible heat flux has dropped to zero. The vertical relative humidity profile as determined by using the horizontally averaged temperature, specific humidity, and pressure, does not exceed $85 \%$. The maximum relative humidity is located directly below the mixed layer top.

[24] These figures show that, even though in the mixed layer approach it is often assumed that the cloud layer characteristics are not affected by the $\mathrm{SCu}$ convection [Neggers et al., 2006; B. J. H. van Stratum et al., submitted manuscript, 2013], the horizontally averaged vertical profiles of $q$ and $\theta_{l}$ in the cloud layer can be affected by the air that is vented from the subcloud layer. Future parametrizations in conceptual mixed layer models or in large-scale atmospheric models could possibly be improved by incorporating this second-order effect, as recently implemented by Gentine et al. [2013].

[25] The evolution of the cloud presence is depicted in Figure $3 \mathrm{a}$. In this figure, the cover and the maximum value of the area fraction for clouds and cloud cores are shown at $1 \mathrm{~min}$ intervals. Here we show that one should not take the total cloud cover as a proxy for the area of $\mathrm{SCu}$ convective transport. The active transport depends on the area fraction of the cloud cores at cloud base height. Since this is determined as the height at which the cloud core area fraction reaches its maximum, the used variable is the maximum cloud core area fraction. As introduced above, $a$ denotes 
OUWERSLOOT ET AL.: SHALLOW CUMULUS TRANSPORT OF REACTANTS

Table 1. Chemical Reaction Scheme Solved by DALES, the Same as in Ouwersloot et al. [2012]

\begin{tabular}{|c|c|c|}
\hline Name & Chemical Equation & Reaction Rate Constant \\
\hline R1 & $\mathrm{O}_{3}+h v \rightarrow \mathrm{O}\left({ }^{1} D\right)+\mathrm{O}_{2}$ & $3.83 \times 10^{-5} \cdot \mathrm{e}^{-\frac{0.575}{\cos (x)}}$ \\
\hline R2 & $\mathrm{O}\left({ }^{1} D\right)+\mathrm{H}_{2} \mathrm{O} \rightarrow 2 \mathrm{OH}$ & $1.63 \times 10^{-10} \cdot \mathrm{e}^{\frac{60}{T}}$ \\
\hline R3 & $\mathrm{O}\left({ }^{1} D\right)+\mathrm{N}_{2} \rightarrow \mathrm{O}_{3}+\mathrm{REST}$ & $2.15 \times 10^{-11} \cdot \mathrm{e}^{\frac{110}{T}}$ \\
\hline R4 & $\mathrm{O}\left({ }^{1} D\right)+\mathrm{O}_{2} \rightarrow \mathrm{O}_{3}$ & $3.30 \times 0^{-11} \cdot \mathrm{e}^{\frac{55}{T}}$ \\
\hline R5 & $\mathrm{NO}_{2}+h v \rightarrow \mathrm{NO}+\mathrm{O}_{3}+\mathrm{REST}$ & $1.67 \times 10^{-2} \cdot \mathrm{e}^{-\frac{0.575}{\cos (X)}}$ \\
\hline R6 & $\mathrm{CH}_{2} \mathrm{O}+h v \rightarrow \mathrm{HO}_{2}+\mathrm{REST}$ & $1.47 \times 10^{-4} \cdot \mathrm{e}^{-\frac{0.575}{\cos (x)}}$ \\
\hline R7 & $\mathrm{OH}+\mathrm{CO} \rightarrow \mathrm{HO}_{2}+\mathrm{CO}_{2}+\mathrm{REST}$ & $2.40 \times 10^{-13}$ \\
\hline R8 & $\mathrm{OH}+\mathrm{CH}_{4} \rightarrow \mathrm{CH}_{3} \mathrm{O}_{2}+\mathrm{REST}$ & $2.45 \times 10^{-12} \cdot \mathrm{e}^{\frac{-1775}{T}}$ \\
\hline R9 & $\mathrm{OH}+\mathrm{C}_{5} \mathrm{H}_{8} \rightarrow \mathrm{RO}_{2}$ & $1.00 \times 10^{-10}$ \\
\hline R10 & $\mathrm{OH}+\mathrm{MVK} \rightarrow \mathrm{HO}_{2}+\mathrm{CH}_{2} \mathrm{O}+\mathrm{REST}$ & $2.40 \times 10^{-11}$ \\
\hline R11 & $\mathrm{HO}_{2}+\mathrm{NO} \rightarrow \mathrm{OH}+\mathrm{NO}_{2}$ & $3.50 \times 10^{-12} \cdot \mathrm{e}^{\frac{250}{T}}$ \\
\hline R12 & $\mathrm{CH}_{3} \mathrm{O}_{2}+\mathrm{NO} \rightarrow \mathrm{HO}_{2}+\mathrm{NO}_{2}+\mathrm{CH}_{2} \mathrm{O}+\mathrm{REST}$ & $2.80 \times 10^{-12} \cdot \mathrm{e}^{\frac{300}{T}}$ \\
\hline R13 & $\mathrm{RO}_{2}+\mathrm{NO} \rightarrow \mathrm{HO}_{2}+\mathrm{NO}_{2}+\mathrm{CH}_{2} \mathrm{O}+\mathrm{MVK}$ & $1.00 \times 10^{-11}$ \\
\hline R14 & $\mathrm{OH}+\mathrm{CH}_{2} \mathrm{O} \rightarrow \mathrm{HO}_{2}+\mathrm{REST}$ & $5.50 \times 10^{-12} \cdot \mathrm{e}^{\frac{125}{T}}$ \\
\hline R15 & $2 \mathrm{HO}_{2} \rightarrow \mathrm{H}_{2} \mathrm{O}_{2}+\mathrm{O}_{2}$ & $k^{b}$ \\
\hline R16 & $\mathrm{CH}_{3} \mathrm{O}_{2}+\mathrm{HO}_{2} \rightarrow$ REST & $4.10 \times 10^{-13} \cdot \mathrm{e}^{\frac{750}{T}}$ \\
\hline R17 & $\mathrm{RO}_{2}+\mathrm{HO}_{2} \rightarrow \mathrm{REST}$ & $1.50 \times 10^{-11}$ \\
\hline R18 & $\mathrm{OH}+\mathrm{NO}_{2} \rightarrow \mathrm{HNO}_{3}$ & $3.50 \times 10^{-12} \cdot \mathrm{e}^{\frac{340}{T}}$ \\
\hline R19 & $\mathrm{NO}+\mathrm{O}_{3} \rightarrow \mathrm{NO}_{2}+\mathrm{O}_{2}$ & $3.00 \times 10^{-12} \cdot \mathrm{e}^{-\frac{1500}{T}}$ \\
\hline $\mathrm{R} 20$ & $\mathrm{OH}+\mathrm{HO}_{2} \rightarrow \mathrm{H}_{2} \mathrm{O}+\mathrm{O}_{2}$ & $4.80 \times 10^{-11} \cdot \mathrm{e}^{\frac{250}{T}}$ \\
\hline $\mathrm{R} 21$ & $\mathrm{OH}+\mathrm{H}_{2} \mathrm{O}_{2} \rightarrow \mathrm{H}_{2} \mathrm{O}+\mathrm{HO}_{2}$ & $2.90 \times 10^{-12} \cdot \mathrm{e}^{\frac{-160}{T}}$ \\
\hline $\mathrm{R} 22$ & $\mathrm{NO}+\mathrm{NO}_{3} \rightarrow 2 \mathrm{NO}_{2}$ & $1.80 \times 10^{-11} \cdot \mathrm{e}^{\frac{110}{T}}$ \\
\hline $\mathrm{R} 23$ & $\mathrm{NO}_{2}+\mathrm{O}_{3} \rightarrow \mathrm{NO}_{3}+\mathrm{O}_{2}$ & $1.40 \times 10^{-13} \cdot \mathrm{e}^{\frac{-2470}{T}}$ \\
\hline R24 & $\mathrm{NO}_{2}+\mathrm{NO}_{3} \rightarrow \mathrm{N}_{2} \mathrm{O}_{5}$ & $k^{c}$ \\
\hline R25 & $\mathrm{N}_{2} \mathrm{O}_{5} \rightarrow \mathrm{NO}_{2}+\mathrm{NO}_{3}$ & $k^{d}$ \\
\hline R26 & $\mathrm{N}_{2} \mathrm{O}_{5}+\mathrm{H}_{2} \mathrm{O} \rightarrow 2 \mathrm{HNO}_{3}$ & $2.50 \times 10^{-22}$ \\
\hline R27 & $\mathrm{N}_{2} \mathrm{O}_{5}+2 \mathrm{H}_{2} \mathrm{O} \rightarrow 2 \mathrm{HNO}_{3}+\mathrm{H}_{2} \mathrm{O}$ & $1.80 \times 10^{-39}$ \\
\hline R28 & $\mathrm{HO}_{2}+\mathrm{O}_{3} \rightarrow \mathrm{OH}+2 \mathrm{O}_{2}$ & $2.03 \times 10^{-16} \cdot\left(\frac{T}{300}\right)^{4.57} \cdot \mathrm{e}^{\frac{693}{T}}$ \\
\hline
\end{tabular}

${ }^{\mathrm{a}} T$ is the absolute temperature in $\mathrm{K}$ and $\chi$ is the solar zenith angle. The unit of first-order reaction rate coefficients is $\mathrm{s}^{-1}$ and that of second-order reaction rate coefficients is $\mathrm{cm}^{3}$ molec ${ }^{-1} \mathrm{~s}^{-1}$. Reaction (R15), (R24), and (R25) have more comprehensive expressions for their reaction rates ${ }^{b, c, d}$. For these expressions, $c_{\text {air }}$ and $c_{\mathrm{H}_{2} O}$ are the concentrations in molec $\mathrm{cm}^{-3}$ for air and $\mathrm{H}_{2} \mathrm{O}$, respectively. MVK represents methyl vinyl ketone and REST represents products and/or secondary fast reactions with reactants that are not specified.

${ }^{\mathrm{b}} k=\left(k_{1}+k_{2}\right) k_{3}, k_{1}=2.2 \times 10^{-13} \cdot \mathrm{e}^{\frac{600}{T}}, k_{2}=1.9 \times 10^{-33} \cdot \mathrm{e}^{\frac{980}{T}} \cdot c_{\text {air }}, k_{3}=1+1.4 \times 10^{-21} \cdot \mathrm{e}^{\frac{2200}{T}} \cdot c_{\mathrm{H}_{2} \mathrm{O}}$. ${ }^{\mathrm{c}} k=0.35 \cdot\left(k_{1} \cdot k_{2}\right) /\left(k_{1}+k_{2}\right), k_{1}=3.6 \times 10^{-30} \cdot\left(\frac{T}{300}\right)^{-4.1} \cdot c_{\text {air }}, k_{2}=1.9 \times 10^{-12} \cdot\left(\frac{T}{300}\right)^{0.2}$.

${ }^{\mathrm{d}} k=0.35 \cdot\left(k_{1} \cdot k_{2}\right) /\left(k_{1}+k_{2}\right), k_{1}=1.3 \times 10^{-3} \cdot\left(\frac{T}{300}\right)^{-3.5} \cdot \mathrm{e}^{\frac{-11000}{T}} \cdot c_{\text {air }}, k_{2}=9.7 \times 10^{14} \cdot\left(\frac{T}{300}\right)^{0.1} \cdot \mathrm{e}^{\frac{-11080}{T}}$.

the height-dependent area fraction and $c$ denotes the cover, considering cloud presence anywhere in the column at a horizontal position. The indices $c$ and $\mathrm{cc}$ indicate sampling over all clouds and sampling over the cloud cores, respectively. Since $c$ considers the presence of clouds in the entire column, $a(z) \leq c$ for any $z$, resulting in the lower $\max a(z)$ compared to $c$. In our numerical experiment, the value of $c_{\mathrm{cc}}$ is on average only $33 \%$ of the value of $c_{c}$ and the maximum $\frac{c_{\mathrm{cc}}}{c_{c}}$ ratio is $60 \%$. Additionally, $\max a_{\mathrm{cc}}(z)$ is on average $36 \%$ compared to $c_{\mathrm{cc}}$. Therefore, in total, $\max a_{\mathrm{cc}}(z)$ divided by $c_{c}$ reaches a maximum of only $30 \%$ and is, when active clouds are present, on average only $12 \%$.

[26] The resulting mass flux by active $\mathrm{SCu}$ transport is shown in Figure 3b. To smooth extremes, the mass flux is averaged over $10 \mathrm{~min}$. The figure shows that the mass flux at $z_{b}$ is usually equal to the maximum mass flux and very close otherwise, agreeing with the vertical mass flux profiles presented in previous studies [Siebesma and Cuijpers, 1995; Vilà-Guerau de Arellano et al., 2005]. In this numerical experiment, the mass flux is strongest between 12 and $14 \mathrm{LT}$. In that period, $M$ is on average $5.0 \mathrm{~cm} \mathrm{~s}^{-1}$, while the average is only $2.1 \mathrm{~cm} \mathrm{~s}^{-1}$ when averaging over all moments during which there is a mass flux. The mass flux peaks at a value of $7.8 \mathrm{~cm} \mathrm{~s}^{-1}$. These magnitudes of the mass flux correspond well to the profiles presented in the aforementioned studies. During this period, the average liquid water path is $16 \mathrm{~g} \mathrm{~m}^{-2}$ and the time averaged maximum relative humidity is $81 \%$.

[27] In this study, we further investigate the impact of mass flux transport on atmospheric reactant mixing ratios in the subcloud layer. Before quantifying this transport, we test our model and analysis by evaluating our resulting parametrizations for $w_{\mathrm{cc}}$ and $q_{\mathrm{cc}}$ and comparing them with the current state-of-the-art parametrizations for $\mathrm{SCu}$ mass flux over land (B. J. H. van Stratum et al., submitted manuscript, 2013). To obtain representative values that are sampled over a sufficiently large number of data points, this analysis is only performed at times that $c_{\mathrm{cc}}>5 \%$. Here equations (7) and (8) are used. However, two new adaptations are made as we found they improved the representativeness of the parametrizations. First, next to evaluating equation (8) with $\sigma_{q, h}$, we evaluated this equation using $\sigma_{q}$ as determined over the entire subcloud layer. Second, to generalize the parametrization to include conditions where the subcloud layer value of $q$ (or, later on, a reactant) is lower than the value at $z_{b}$, we multiplied by the sign of $-\Delta q$. In our study this is not needed for $q$, since $\Delta q$ is always negative as the mixed layer $q$ is 

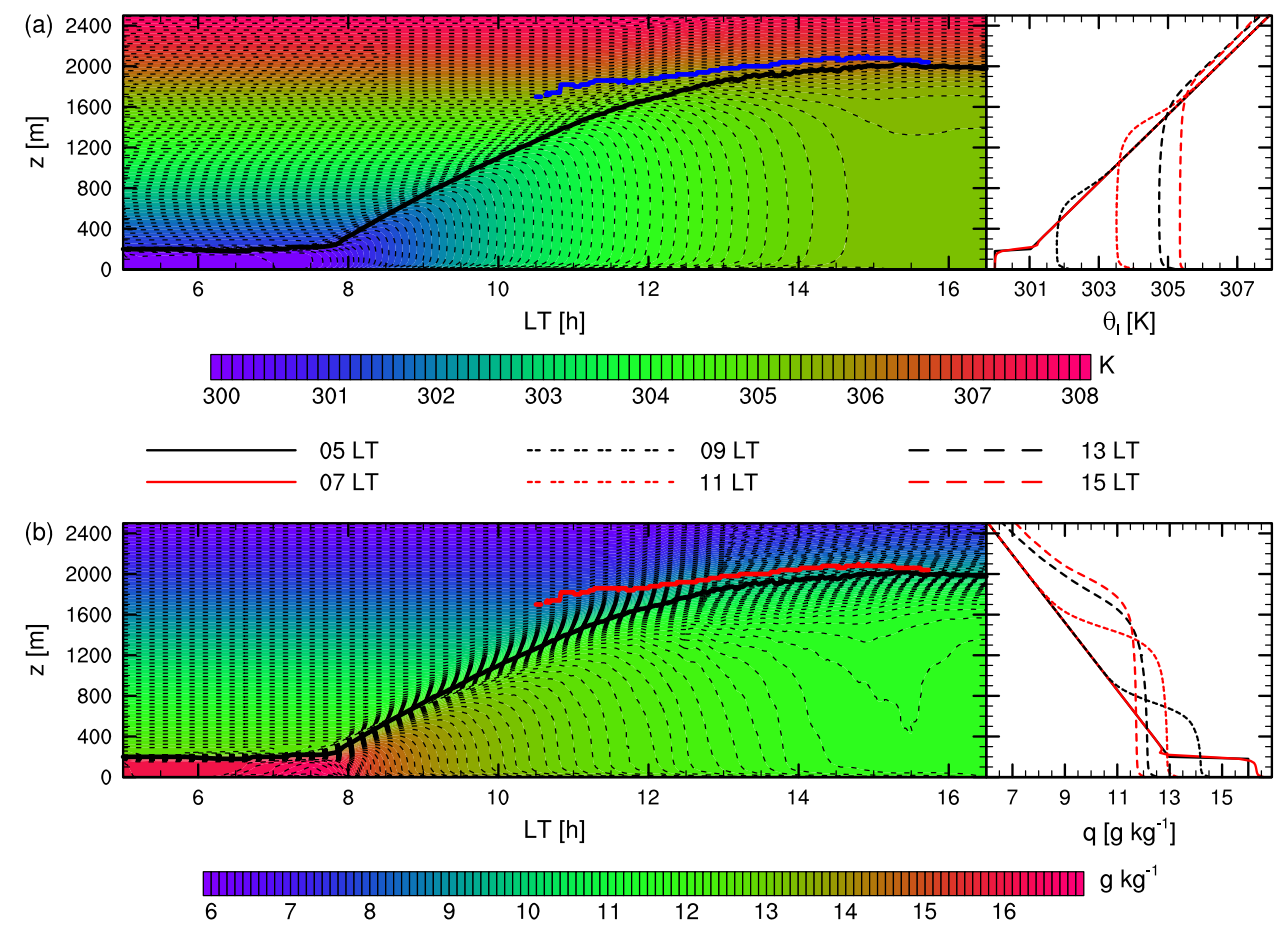

Figure 2. The vertical profile evolution of (a) liquid water potential temperature, $\theta_{l}$ and (b) specific humidity, $q$. The left panels show horizontal averages as a function of local time and height. The diagnosed mixed layer height is indicated by the black line. The cloud base height, $z_{b}$, is presented as a blue line in Figure $2 \mathrm{a}$ and as a red line in Figure $2 \mathrm{~b}$. The right panels show the horizontally averaged instantaneous vertical profiles at intervals of $2 \mathrm{~h}$.

higher than the free tropospheric value and the surface moisture flux is never negative. However, this addition makes the parametrization more general and it will be needed to represent atmospheric reactant transport using the same framework. The resulting dependencies of $w_{\mathrm{cc}}$ and $q_{\mathrm{cc}}$ (compared to $\langle q\rangle$ ) are displayed in Figure 4. The linear fit for both graphs is forced through the origin, corresponding to the expressions in equations (7) and (8). To evaluate the quality of the fit, we make use of the index of agreement, $d$ [Willmott, 1981]. This statistical diagnostic expresses the degree to which an observed variable (e.g., $w_{\mathrm{cc}}$ ) can be accurately estimated by a predicted variable (e.g., $\lambda w_{*}$ ), rather than the correlation between the variables. The use of the common $R^{2}$ can yield biased values, because the linear fit used is forced through the origin, so that even the averages of the observed and predicted values do not have to be equal. In total, this can even lead to negative $R^{2}$ for some of the tested parametrizations. In accord with B. J. H. van Stratum et al. (submitted manuscript, 2013) for three different cases over land, we find

$$
w_{\mathrm{cc}}=0.84 w_{*}
$$

with $d=0.94$. For the representation of $q$, we find only a minor difference. Instead of a factor 0.51 , our results show

$$
q_{\mathrm{cc}}-<q>=0.53 \sigma_{q, h}
$$
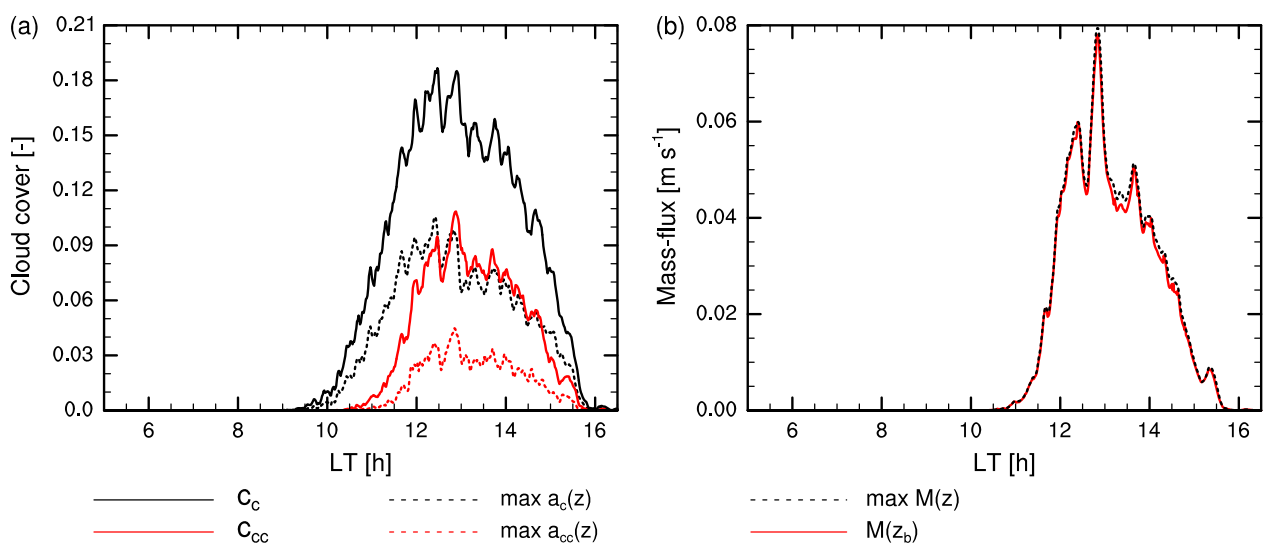

Figure 3. The evolution of (a) the cover and area fraction of SCu clouds and cloud cores, and (b) the mass fluxes by $\mathrm{SCu}$ convection. For the latter, the values at height $z_{b}$ and the maximum mass flux are presented. 

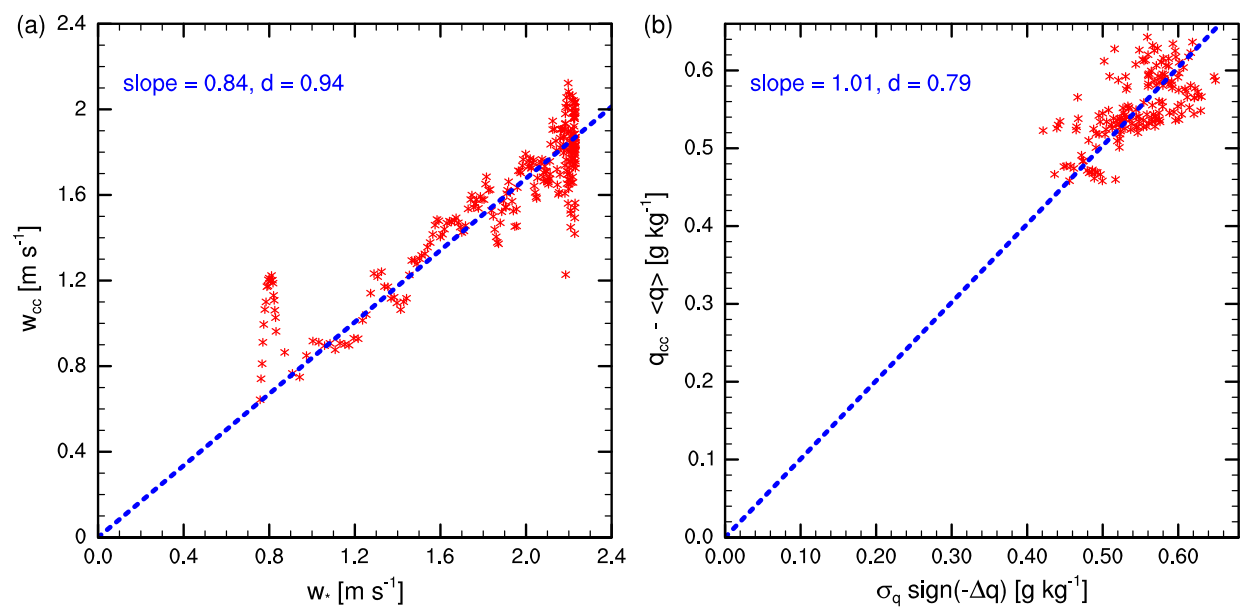

Figure 4. Parametrization for (a) $w_{\mathrm{cc}}$ and (b) $q_{\mathrm{cc}}-\langle q\rangle$. The blue dashed lines indicate the linear regression fits, forced through $(0,0)$. The red asterisks are model data sampled at 1 min intervals. The slopes and indexes of agreement, $d$, are indicated.

with $d=0.73$. A better index of agreement, $d=0.79$, is found relating $q_{\mathrm{cc}}$ to the total $\sigma_{q}$. This results in

$$
q_{\mathrm{cc}}-<q>=\zeta_{2} \sigma_{q}, \quad \zeta_{2}=1.01 .
$$

[28] In short, our results show that we can reproduce the parametrizations for the mass flux of moisture, even though the numerical experiment is not similar to the ones presented before. These previous studies, which include the Atmospheric Radiation Measurement - Southern Great Plains [Brown et al., 2002], Small Cumulus and Microphysics Study [Neggers et al., 2003], and Gulf of Mexico Atmospheric Composition and Climate Study [Angevine et al., 2010] experiments, were situated at temperate latitudes with maximum mixed layer heights below $1500 \mathrm{~m}$, while the case under study is situated near the equator and has a maximum mixed layer height of $2000 \mathrm{~m}$. The fact that analyses of different cases yield similar parametrizations confirms the validity and robustness of the proposed expressions. However, our results also suggest that a more representative parametrization might exist for $q_{\mathrm{cc}}$ by using the standard deviation that is calculated over the entire subcloud layer. Future studies could investigate whether this improvement is general or case dependent.

\subsection{Spatial Distribution of Atmospheric Compounds in the Subcloud Layer}

[29] As shown by the budget equations (5) and (6), the contribution of the mass flux to the evolution of an arbitrary scalar, $\phi$, is determined by the deviation of the cloud core averaged value compared to a reference value, i.e., respectively $\phi_{\mathrm{cc}}-<\phi>$ and $\phi_{\mathrm{cc}}-\bar{\phi}\left(z_{b}\right)$ (as $z_{b}$ is used as a proxy for $h^{+}$). To parametrize these contributions, first, the source of these differences should be understood. Even if the subcloud layer was perfectly well mixed, the contribution of $\phi_{\mathrm{cc}}-\bar{\phi}\left(z_{b}\right)$ would be expected to be nonzero. After all, in that case, the value of $\phi_{c c}$ is equal to the value of $\phi$ in the thermals that originate from the subcloud layer and therefore equal to $\langle\phi\rangle$. In turn, $\bar{\phi}\left(z_{b}\right)$ is the value for $\phi$ at cloud base height, being unequal to $\langle\phi\rangle$. However, if the subcloud layer were perfectly well mixed, the contribution in the other budget, governed by $\phi_{\mathrm{cc}}-\langle\phi\rangle$, would be 0 . Why this is not the case can be deduced from Figure 5. In this figure, the hourly and $y$ direction averaged mixing ratios are shown for three different simulated chemical species and two different time periods. The two chosen periods are between $1200 \mathrm{LT}$ and $1300 \mathrm{LT}$, and between $1300 \mathrm{LT}$ and $1400 \mathrm{LT}$, since the mass flux is relatively largest (see Figure 3b). In Figures 5a and $5 \mathrm{~b}$, the projections are shown for the atmospheric compound BLS. This inert tracer has no active surface exchange and was initialized at $0 \mathrm{ppb}$ above the mixed layer. Even though the compound was initially well mixed throughout the subcloud layer, in this figure, clear spatial patterns can be discerned. This spatial distribution is driven by the turbulence characteristics of the subcloud layer. The air flow is shown superimposed on the BLS mixing ratio contour plots. As mentioned in section 1, the $\mathrm{SCu}$ clouds stimulate large-scale structures in the subcloud layer [Kim et al., 2012], which are very similar in shape compared to the circulations induced by land surface heterogeneity [Patton et al., 2005; Ouwersloot et al., 2011]. Higher mixing ratios are found near the $\frac{x}{\lambda}$ positions $-0.25,0.5$, and 1 . At these locations, upward moving thermals are present that drive the $\mathrm{SCu}$ convection. While the thermals become narrower in the period 1300-1400 LT compared to 1200-1300 LT, their positions do not change significantly. As the clouds on top of the thermals vent the air from the subcloud layer, air in that layer will tend to converge to those locations, strengthening the thermals and fixing their positions, a process which was hinted at in observational studies [LeMone and Pennell, 1976]. In the cloudless regions, the air descends (with a velocity of maximum $0.5 \mathrm{~m} \mathrm{~s}^{-1}$ ), transporting the air that is entrained at the top of the subcloud layer toward the surface. This air is characterized by lower (cloud layer) mixing ratios of BLS. The subcloud layer averaged mixing ratio, $\langle\phi\rangle$, is a value between the mixing ratios in the upward moving thermals, $\phi_{\mathrm{cc}}$, and in the downward moving motions. As a consequence, in equation (5), $\phi_{\mathrm{cc}}>\langle\phi\rangle$ for the BLS mixing ratio.

[30] Figures 5c and 5d show that the same structure is present for the mixing ratio of INERT. This inert chemical species is initialized with a mixing ratio of $0 \mathrm{ppb}$ everywhere and is continuously emitted from the surface. Since the emitted species are transported to the upper part of the subcloud 

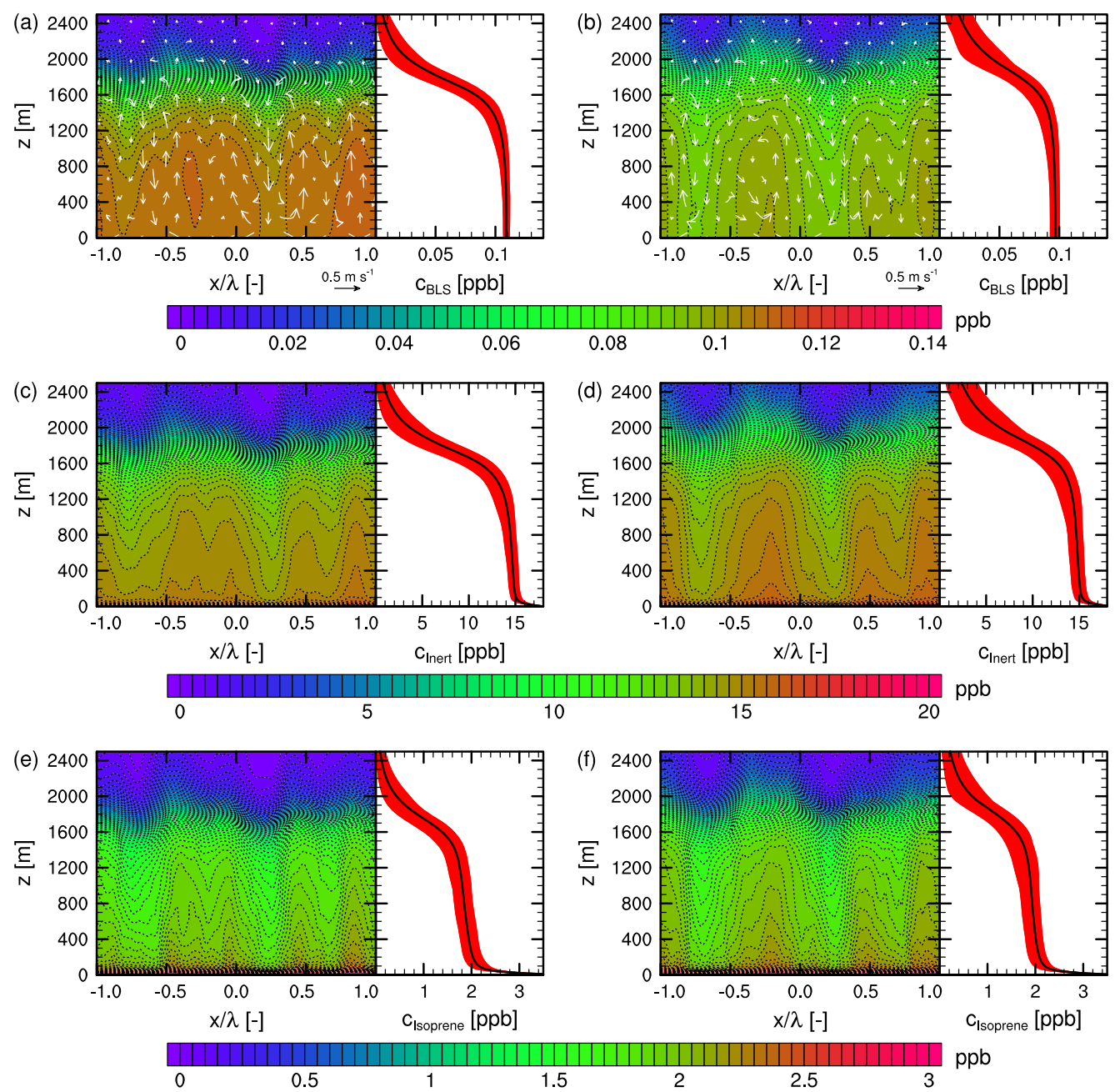

Figure 5. Mixing ratios of the chemical species (a,b) BLS, (c,d) INERT, and (e,f) isoprene. The left panels with color contours show the mixing ratios averaged over the $y$ direction and over time. The period of averaging is between 1200 LT and 1300 LT (Figures 5a, 5c, and 5e) and between 1300 LT and 1400 LT (Figures 5b, 5d, and 5f). In the right panels, the mixing ratios are additionally averaged in the $x$ direction. The red ranges in the right panels show the spread in the $x$ direction of the temporal and $y$ averaged values. The $x$ coordinate is scaled over a distance of $6.4 \mathrm{~km}$. The wind direction and magnitude are indicated by vectors (Figures $5 \mathrm{a}$ and $5 \mathrm{~b}$ ).

layer by thermals, the difference between the mixing ratio in the thermals compared to the mixed layer averaged mixing ratio is increased. However, even though the spatial segregation is enhanced, in general the same effects occur as for the BLS mixing ratio. As evidenced by Figures 5e and 5f, the same structures also appear for the chemically active species isoprene, which is also emitted from the surface.

[31] In short, the combination of entrained cloud layer air and the induced large-scale structures cause the difference between $\phi_{\mathrm{cc}}$, which is characterized by $\phi$ in the thermals and $\langle\phi\rangle$. The corresponding spatial distribution of $\phi$ results in organized variance that is stronger than the turbulence related variance and therefore dominates the total variance of $\phi$ in the boundary layer. As a result, the magnitude of $\sigma_{\phi}$, calculated either over the entire subcloud layer or just below the inversion, seems a good proxy to estimate $\phi_{\mathrm{cc}^{-}}<\phi>$, confirming the assumption of B. J. H. van Stratum et al. (submitted manuscript, 2013). In turn, this variance is caused by the entrainment of cloud layer air into the subcloud layer, as first suggested by Neggers et al. [2007]. Here we should note that the difference between the cloud core average and the average at cloud base height $\left(\phi_{\mathrm{cc}}-\bar{\phi}\left(z_{b}\right)\right)$ is mainly governed by the difference between the average at cloud base height and the subcloud layer averaged value $\left(\bar{\phi}\left(z_{b}\right)-<\phi>\right)$, since the former expression is equal to the difference between the cloud core average and the subcloud layer averaged value $\left(\phi_{\mathrm{cc}}-\right.$ $\langle\phi\rangle$ ) minus the latter expression. Compared to the other terms, the difference between the cloud core average and the subcloud layer average is relatively small. For parametrizing the pumping budget expressed by equation (6), $\phi_{\mathrm{cc}}-\bar{\phi}\left(z_{b}\right)$ therefore scales best with $\bar{\phi}\left(z_{b}\right)-\langle\phi\rangle$, rather than with the standard deviation of the scalar $\left(\sigma_{\phi}\right)$.

\subsection{Importance of $\mathrm{SCu}$ Convection}

[32] Here we focus on the direct contribution of the mass flux to the evolution of $\phi$, i.e., $\frac{-M\left(\phi_{\mathrm{cc}}-\langle\phi|\right)}{h}$ and $\frac{-M\left(\phi_{\mathrm{cc}}-\bar{\phi}\left(h^{+}\right)\right)}{h}$ 
for equations (5) and (6), respectively. Note that related to the mass flux, the subcloud layer height development, $\frac{d h}{d t}$, is affected as well (see equation (4)). Budget equation (5), referred to as venting budget, divides the exchange at the top of the subcloud layer into air that is entrained with flow rate $w_{e}$ and air that escapes the subcloud layer with flow rate $M$, therefore representing the air flows across the interface between cloud and subcloud layer. Budget equation (6), referred to as pumping budget, divides this exchange into incorporating air from the cloud layer into the subcloud layer by growth of the subcloud layer, and an additional circulation of air with flow rate $M$. This circulation transports air characterized by $\phi_{\mathrm{cc}}$ out of the subcloud layer and replaces it with air characterized by $\bar{\phi}\left(h^{+}\right)$, acting like a pump. An advantage of this expression is that, in contrast to the entrainment velocity, the tendency of the mixed layer height $\left(\frac{\mathrm{d} h}{\mathrm{~d} t}\right)$ can be determined directly from observational or numerical data. While we will evaluate the parametrizations of the mass flux transport for both budgets (section 3.4), only the more applicable pumping budget is considered when analyzing the vertical transport profiles from LES data (section 3.5).

[33] To determine the importance of the mass flux transport, we calculate its contributions to the temporal evolutions of $q$ and the mixing ratios. They are divided by $q$ or the mixing ratios themselves to result in a contribution that is expressed as a percentage change per hour. In general, the contribution of the pumping budget mass flux term is higher than the contribution of the venting budget mass flux term. For example, the pumping contribution for $q$ is $-2.5 \% \mathrm{~h}^{-1}$, while the venting contribution is $-0.4 \% \mathrm{~h}^{-1}$. The reason is that at the interface between the cloud and subcloud layer, the most important contribution to the budget equations is the air that is entrained in surplus of $\frac{\mathrm{d} h}{\mathrm{~d} t}$, i.e., with flow rate $M$ (see equation (4)). This contribution $(-M \Delta \phi)$ is incorporated in the entrainment term in the venting budget, and in the mass flux term in the pumping budget. Even for the pumping budget, the contributions to the reactant mixing ratio tendencies are of the order of $1 \% \mathrm{~h}^{-1}$ and therefore not significant. In our analysis, based on TROFFEE data, there are a few exceptions that change mixing ratios on average more than $5 \%$ per hour due to the mass flux circulation (pumping budget). Focusing on those reactants whose chemical lifetime is not shorter than the turbulent time scale $(\sim 15 \mathrm{~min})$, this is the case for the INERT species $\left(-6.4 \% \mathrm{~h}^{-1}\right)$, isoprene $\left(-8.5 \% \mathrm{~h}^{-1}\right)$, and the inert tracer BLS $\left(-5.9 \% \mathrm{~h}^{-1}\right)$. These contributions can be considered minor but nevertheless significant. The corresponding maximum instantaneous contributions during the presence of active $\mathrm{SCu}$ clouds are for the respective species -11.4 (INERT), -15.1 (isoprene), and $-10.6 \% \mathrm{~h}^{-1}$ (BLS).

[34] Note that the BLS and FTS tracers were initialized such that, at every location, the sum of their mixing ratios was $1 \mathrm{ppb}$. Additionally, they are not influenced by any surface exchange or chemical transformations. Therefore, the mass flux contributions for these two tracers are equal in magnitude and only differ in sign. However, at the time the active clouds appear, the mixed layer height is much larger than its initial value. Therefore, the mixing ratios of BLS and FTS approach their initial free tropospheric mixing ratios (i.e., 0 and $1 \mathrm{ppb}$, respectively). During the most active $\mathrm{SCu}$ convection (1200-1400 LT) their mixed layer averaged mixing ratios are, respectively, 0.1 and $0.9 \mathrm{ppb}$. As a result, the same mass flux contribution to the budget yields a much lower relative change per hour for FTS than for BLS.

\subsection{Parametrizing Reactant Transport}

[35] Similar to $q$ in section 3.1, the mixing ratios of the atmospheric compounds in the cloud core are parametrized compared to a reference value, being either $\left\langle\phi>\right.$ or $\bar{\phi}\left(z_{b}\right)$. We analyze the resulting expressions for two cases: the standard case (SC) that is described in section 2.3 and a numerical setup in which the scattering of UV radiation by clouds has been turned off, effectively resulting in transparent clouds (TC). As will be discussed later in this section, several chemical species (especially $\mathrm{O}_{3}, \mathrm{NO}$, and $\mathrm{NO}_{2}$ ) are particularly sensitive to this modification of the UV radiation below the clouds. We tested different parametrizations for both $\phi_{\mathrm{cc}}-<\phi>$ and $\phi_{\mathrm{cc}}-\bar{\phi}\left(z_{b}\right)$, using linear functions. For $\phi_{\mathrm{cc}}-\langle\phi\rangle$, the most realistic results were obtained by expressions as a function of $\sigma_{\phi} \operatorname{sign}(-\Delta \phi)$. This agrees with the discussion in section 3.2. $\phi_{\mathrm{cc}}-\bar{\phi}\left(z_{b}\right)$ is best parametrized as a function of $\bar{\phi}\left(z_{b}\right)-\langle\phi\rangle$. Here $\sigma_{\phi}$ is the standard deviation of scalar $\phi$ that is calculated over the entire subcloud layer. This differs from previous studies (B. J. H. van Stratum et al., submitted manuscript, 2013), where $\sigma_{\phi, h}$ is used. In this study, using $\sigma_{\phi, h}$ resulted in slightly lower values for the indices of agreement, $d$, and slopes of the linear fits that are approximately $\frac{1}{2}$ times the slopes found for expressions based on the total $\sigma_{\phi}$.

[36] The relations between $\sigma_{\phi}$ and $\phi_{c c}-\langle\phi\rangle$, and between $\bar{\phi}\left(z_{b}\right)-\langle\phi\rangle$ and $\phi_{\mathrm{cc}}-\bar{\phi}\left(z_{b}\right)$ are visualized for different atmospheric compounds in Figures 6 and 7. The presented results are a first step in developing a general expression for the mass flux transport of atmospheric reactants. Figure 6 shows the parametrization based on isoprene, $\mathrm{CO}$, and the inert tracers INERT and BLS for the standard case. For visualization purposes, the BLS mixing ratios are multiplied by 1000 . For these atmospheric compounds, the perturbation of UV radiation by clouds has no significant impact on the parametrization, producing nearly identical results for the TC numerical experiment (not shown). Additionally, the constants for the expressions that are derived from these four compounds are very similar to those derived for $q$. For the venting budget, the slope is found to be 0.92 , while it was 1.01 for $q$. For the pumping budget, the match is even closer with a slope of -1.23 for the atmospheric compounds, while it was -1.20 for $q$ (not shown). Even though not all data points lay perfectly on the regression line, Figure 6 corroborates that $\phi_{\mathrm{cc}}-\left\langle\phi>\right.$ and $\phi_{\mathrm{cc}}-\bar{\phi}\left(z_{b}\right)$ can be adequately represented for these atmospheric compounds.

[37] However, not all reactants comply that well with the expressions that were derived. The parametrizations for $\mathrm{O}_{3}$, $\mathrm{NO}_{2}, \mathrm{OH}$, and $\mathrm{H}_{2} \mathrm{O}_{2}$ are shown in Figure 7. These four reactants all respond quickly to changes in UV radiation through reactions $\mathrm{R} 1, \mathrm{R} 5$, and $\mathrm{R} 6$ in Table 1 . Note that the chemical lifetimes of $\mathrm{NO}_{2}(\sim 3 \mathrm{~min})$ and $\mathrm{OH}(\sim 0.15 \mathrm{~s})$ are short compared to the turbulent time scale. $\mathrm{OH}$ is multiplied by 1000 in the figure for visualization. In the subcloud layer, the coherent thermals that are the roots of the $\mathrm{SCu}$ clouds are located exactly at these shaded positions as there is no mean horizontal wind velocity and we consider onedimensional radiation effects. Therefore the mixing ratios of 

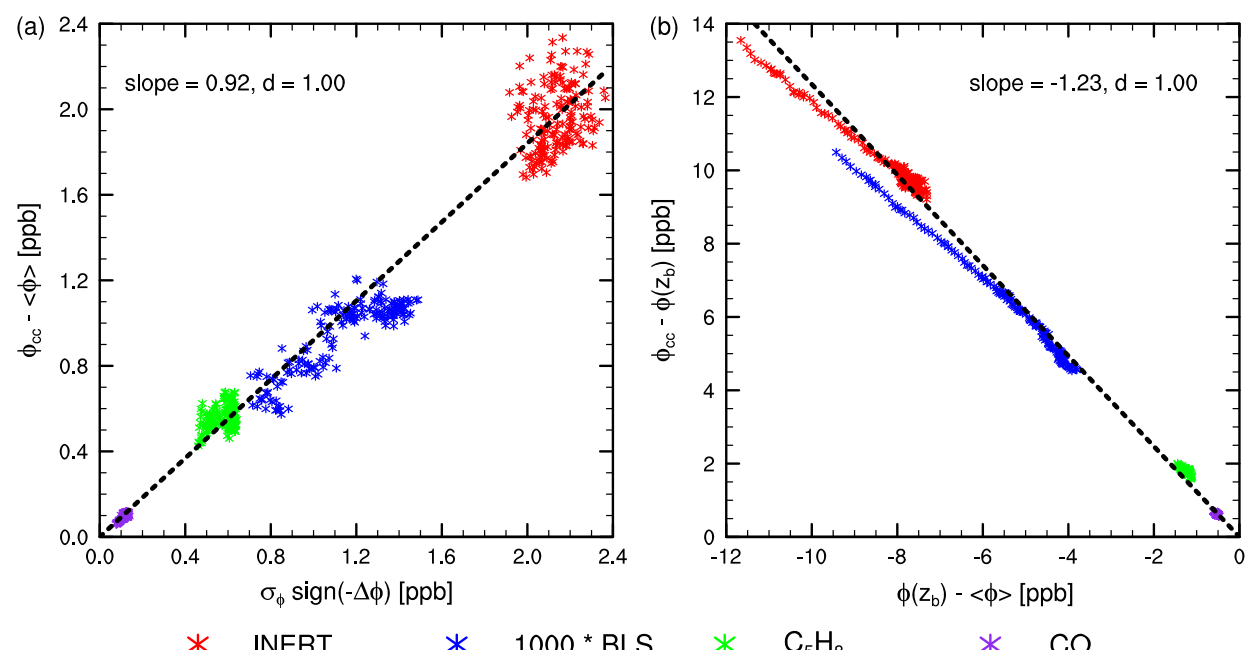

Figure 6. Parametrization for (a) $\phi_{\mathrm{cc}}-\langle\phi\rangle$ (related to equation (5)) as a function of $\sigma_{\phi}$ times the sign of $-\Delta \phi$ and (b) $\phi_{\mathrm{cc}}-\bar{\phi}\left(z_{b}\right)$ (related to equation (6)) as a function of $\bar{\phi}\left(z_{b}\right)-\langle\phi\rangle$. The evaluated numerical experiment is the standard case (SC). The values for $\phi$ represent the mixing ratios of INERT, $\mathrm{BLS}_{2} \mathrm{C}_{5} \mathrm{H}_{8}$, and $\mathrm{CO}$. The black dashed lines indicate the linear regression fits through all (unscaled) data, forced through $(0,0)$. The asterisks are data sampled at $1 \mathrm{~min}$ intervals. The slopes and indexes of agreement, $d$, are indicated.

the UV dependent reactants in those thermals, and subsequently in the cloud cores, are shifted from their equilibria [Vilà-Guerau de Arellano et al., 2005]. Subsequently, the transported air by SCu convection is more representative for lower UV conditions than for the average subcloud layer conditions. For the venting budget, the atmospheric compounds cannot be parametrized using the proposed linear relationship (e.g., for $\mathrm{H}_{2} \mathrm{O}_{2}$ the slope in Figure 7 a should rather be 0.02). However, the compounds do satisfy a linear relationship for the pumping budget, albeit with a different slope than derived before. This slope, mainly governed by $\mathrm{O}_{3}$ due to the magnitude of its differences in mixing ratio between cloud and subcloud layer, is much closer to -1 and actually implies that $\phi_{\mathrm{cc}}$ is closer to $\langle\phi\rangle$. When these reactants are eventually transported out of the coherent thermals or clouds toward an area above which no cloud is present, the equilibria are quickly restored. Therefore, this misrepresentation does not significantly influence our results. However, the results also show that the actual mass flux transport of individual chemical species to the cloud layer depends on a more complex combination of dynamics, the UV radiation modification by clouds, and the chemical pathways.

[38] Using the TC numerical experiment, we demonstrate that the standard expressions can indeed be applied if the modification of the UV radiation by clouds is not active. In this case, the temporary departure of the UV dependent reactants, compared to their equilibrium mixing ratios under subcloud layer averaged conditions, does not occur. In Figures $7 \mathrm{c}$ and $7 \mathrm{~d}$ the resulting parametrizations are shown. The slopes for the venting budget and pumping budget are, with respectively 0.89 and -1.19 , very close to the slopes found in Figure 6 for the non-UV-dependent atmospheric compounds. This confirms that the original deviations found for chemical reactive species in the SC numerical experiment are indeed caused by temporary modifications induced by UV radiation, and that, consequently, the parametrizations for transport by $\mathrm{SCu}$ convection are valid.
[39] Apart from clustering atmospheric compounds, parametrizations are determined per individual species, except for the background atmospheric compounds $\mathrm{N}_{2}, \mathrm{O}_{2}$, and $\mathrm{H}_{2} \mathrm{O}$. The resulting slopes and corresponding indices of agreement are listed in Table 2. Even though Figures 6 and 7 show that multiple atmospheric compounds approximately follow one derived parametrization, this table indicates that the derived slopes differ depending on which compound is used. For individual species (e.g., NO), the scaling can be completely different from the general derived expression. The scaling even differs between the inert atmospheric compounds INERT and BLS/FTS. These species only differ in initial profiles and surface exchange. However, when grouping all atmospheric compounds, generic expressions are derived that read

$$
\phi_{\mathrm{cc}}-\langle\phi\rangle \approx \xi \sigma_{\phi} \operatorname{sign}(-\Delta \phi), \quad \xi=0.91
$$

and

$$
\phi_{\mathrm{cc}}-\bar{\phi}\left(z_{b}\right) \approx \xi_{2}\left(\bar{\phi}\left(z_{b}\right)-\langle\phi\rangle\right), \quad \xi_{2}=-1.23 .
$$

Some significant deviations from this line can be found for the venting budget for the standard case (not shown), but these disappear for the TC numerical experiment, implying that these excursions are caused by local deviations from chemical equilibria related to UV radiation. To represent $\phi_{\mathrm{cc}}$, these scalings would give satisfactory results for the individual reactant mixing ratios under the investigated dynamical conditions. However, the slopes in the expressions, both for the dynamical variables ( $w_{\mathrm{cc}}$ and $q_{\mathrm{cc}}$ ) and for the mixing ratios, can change if specific conditions are altered. This will be demonstrated for heterogeneous surface forcings in section 3.6. Therefore, it is recommended in future research to test the parametrizations for different regions and under different dynamical and chemical conditions.

[40] Finally, since the slopes of the regression line are determined using the least squares method, the derived slopes for the parametrizations are mainly governed by the atmospheric compounds with the largest difference between 

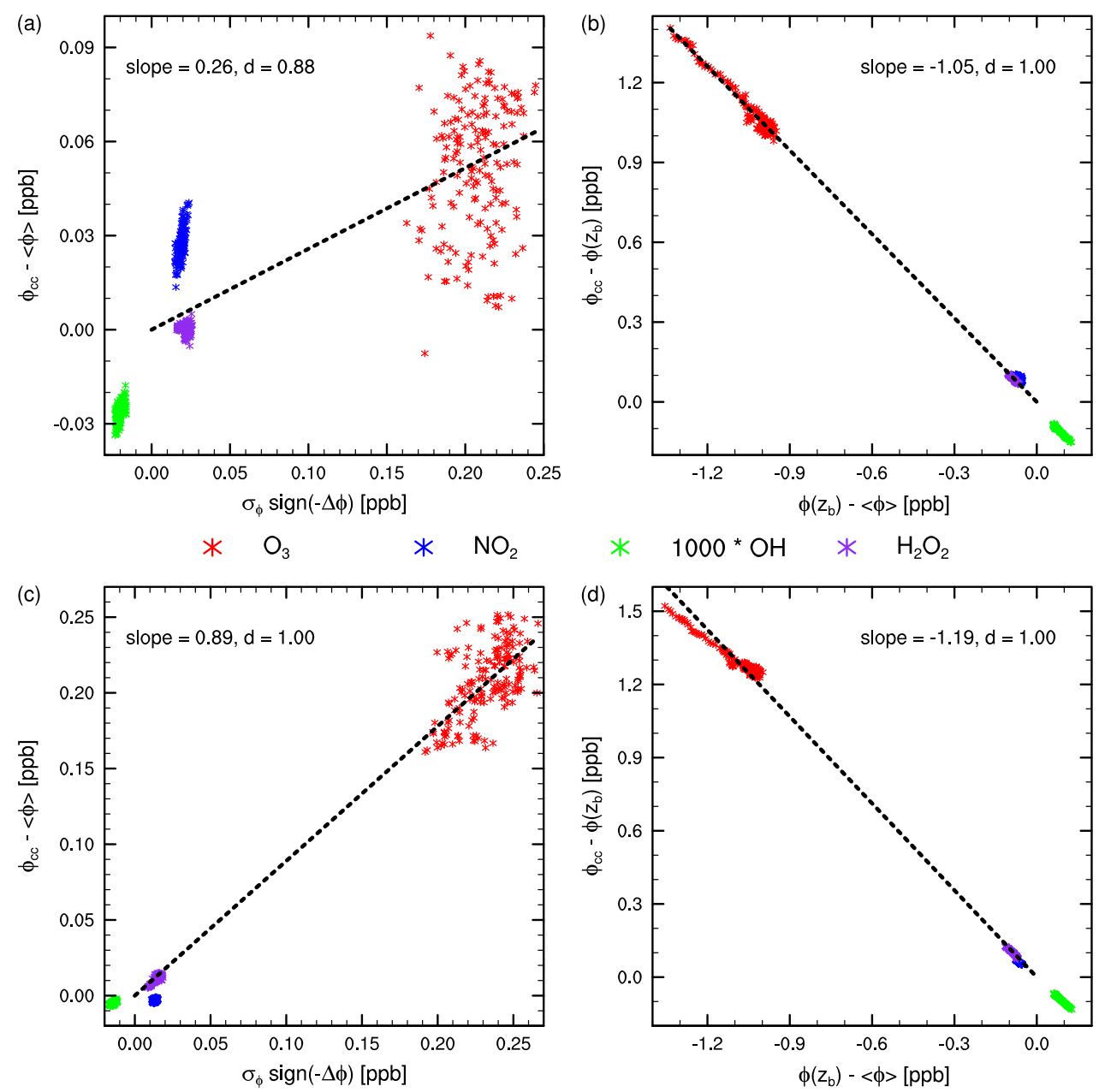

Figure 7. Parametrization for (a,c) $\phi_{\mathrm{cc}}-\langle\phi\rangle$ (related to equation (5)) as a function of $\sigma_{\phi}$ times the sign of $-\Delta \phi$ and $(\mathrm{b}, \mathrm{d}) \phi_{\mathrm{cc}}-\bar{\phi}\left(z_{b}\right)$ (related to equation (6)) as a function of $\bar{\phi}\left(z_{b}\right)-<\phi>$. Two different numerical experiments are evaluated: the standard case (Figures $7 \mathrm{a}$ and $7 \mathrm{~b}$ ) and one in which the UV scattering by clouds has been disabled (Figures 7c and 7d). The values for $\phi$ represent the mixing ratios of $\mathrm{O}_{3}, \mathrm{NO}_{2}, \mathrm{OH}$, and $\mathrm{H}_{2} \mathrm{O}_{2}$. The black dashed lines indicate the linear regression fits through all (unscaled) data, forced through $(0,0)$. The asterisks are data sampled at $1 \mathrm{~min}$ intervals. The slopes and indexes of agreement, $d$, are indicated.

$\phi_{\mathrm{cc}}$ and the reference value, which is INERT in this study. Additionally, due to the different orders of magnitude in the mixing ratios of the atmospheric compounds, statistical variables, like $\mathrm{R}^{2}$ and the index of agreement, which describe the regression lines for these combined compounds are artificially forced to 1 . In short, this is because these statistical variables describe how much of the variance in the data set can be explained by the regression and they therefore increase if the variance in the data set increases.

\subsection{Capturing Vertical Transport}

[41] The previously determined expressions to parametrize $\phi_{\mathrm{cc}}$ were derived to represent the vertical transport of specific humidity and atmospheric reactants. In section 2.1.1, it was stated (after Siebesma and Cuijpers [1995]) that in the cloud layer, the vertical transport is dominated by transport in the cloud cores. Furthermore, in these cloud cores, turbulent transport is considered to be negligible compared to the organized transport, which is governed by the mass flux. Here we study the ability of the parametrization for $\phi_{\mathrm{cc}}$ to reproduce the vertical transport. To directly compare the mass flux transport to the total vertical transport, as expressed by equation (3) and discussed in section 2.1.2, the transport as used in the pumping budget is evaluated. To predict the organized $\mathrm{SCu}$ transport of any scalar, the parametrization of equation (13) and the diagnosed $M$ are multiplied, $M\left(\phi_{\mathrm{cc}}-\bar{\phi}\left(z_{b}\right)\right)$.

[42] The representativeness of the organized transport in the $\mathrm{SCu}$ cloud cores for the total vertical transport in the cloud layer has already been demonstrated for $\theta_{l}$ and $q$ by Siebesma and Cuijpers [1995]. This has been confirmed in our numerical experiments (not shown). The focus is to represent the vertical transport of atmospheric reactants. In contrast to the dynamical variables, the reactant mixing ratios do not affect $M$. Additionally, the transported mixing ratios are influenced by extra factors (e.g., chemistry and UV radiation). Therefore, differences can be expected. For the evaluation of the vertical transport in DALES, the vertical fluxes are averaged between 1200 and 1300 LT. Organized transport by $\mathrm{SCu}$ convection is most active in the numerical 
Table 2. Parametrizations of Mixing Ratios, Denoted by $\phi$, in the Cloud Cores ${ }^{\mathrm{a}}$

\begin{tabular}{lcccc}
\hline & \multicolumn{2}{c}{$\phi_{\mathrm{cc}}-\langle\phi>$ versus } & $\sigma_{\phi} \operatorname{sign}(-\Delta \phi)$ & \multicolumn{2}{c}{$\phi_{\mathrm{cc}}-\bar{\phi}\left(z_{b}\right)$ versus $\bar{\phi}\left(z_{b}\right)-\langle\phi\rangle$} \\
Reactant & $\mathrm{SC}$ & $\mathrm{TC}$ & $\mathrm{SC}$ & $\mathrm{TC}$ \\
\hline $\mathrm{INERT}$ & $0.92(0.50)$ & $0.92(0.50)$ & $-1.23(0.98)$ & $-1.23(0.98)$ \\
$\mathrm{O}_{3}$ & $0.25(0.26)$ & $0.89(0.72)$ & $-1.05(0.99)$ & $-1.19(0.95)$ \\
$\mathrm{O}^{\mathrm{ID}}$ & $1.66(0.64)$ & $-2.51(0.93)$ & $-5.13(0.52)$ & $0.44(0.15)$ \\
$\mathrm{NO}$ & $1.23(0.46)$ & $-1.97(0.02)$ & $-8.06(0.52)$ & $5.09(0.02)$ \\
$\mathrm{NO}_{2}$ & $1.45(0.74)$ & $-0.23(0.08)$ & $-1.45(0.87)$ & $-0.95(0.99)$ \\
$\mathrm{CH}_{4}$ & $0.94(0.87)$ & $0.86(0.87)$ & $-1.21(0.85)$ & $-1.18(0.89)$ \\
$\mathrm{CH}_{2} \mathrm{O}$ & $0.75(0.75)$ & $0.84(0.79)$ & $-1.14(0.95)$ & $-1.16(0.92)$ \\
$\mathrm{CH}_{3} \mathrm{O}_{2}$ & $2.12(0.58)$ & $1.74(0.45)$ & $-1.53(0.94)$ & $-1.40(0.96)$ \\
$\mathrm{MVK}$ & $0.79(0.73)$ & $0.89(0.78)$ & $-1.16(0.96)$ & $-1.19(0.94)$ \\
$\mathrm{C}_{5} \mathrm{H}_{8}$ & $0.96(0.64)$ & $0.86(0.70)$ & $-1.46(0.84)$ & $-1.41(0.91)$ \\
$\mathrm{RO}_{2}$ & $-0.58(0.33)$ & $1.43(0.58)$ & $-0.84(0.93)$ & $-1.34(0.97)$ \\
$\mathrm{OH}$ & $1.31(0.75)$ & $0.34(0.60)$ & $-1.34(0.97)$ & $-1.06(1.00)$ \\
$\mathrm{HO}_{2}$ & $-1.56(0.25)$ & $-0.30(0.18)$ & $5.30(0.17)$ & $-0.60(0.76)$ \\
$\mathrm{CO}$ & $0.84(0.91)$ & $0.84(0.88)$ & $-1.18(0.94)$ & $-1.16(0.95)$ \\
$\mathrm{REST}$ & $0.59(0.88)$ & $0.85(0.91)$ & $-1.13(0.99)$ & $-1.18(0.98)$ \\
$\mathrm{HNO}_{3}$ & $0.93(0.94)$ & $0.87(0.92)$ & $-1.21(0.96)$ & $-1.18(0.96)$ \\
$\mathrm{H}_{2} \mathrm{O}_{2}$ & $0.02(0.02)$ & $0.77(0.91)$ & $-1.00(1.00)$ & $-1.13(1.00)$ \\
$\mathrm{NO}_{3}$ & $0.34(0.47)$ & $-1.53(0.99)$ & $-1.37(0.39)$ & $-0.21(0.20)$ \\
$\mathrm{N}_{2} \mathrm{O}_{5}$ & $-3.59(0.86)$ & $-2.56(0.99)$ & $9.02(0.69)$ & $1.88(0.10)$ \\
$\mathrm{BLS}_{2}$ FTS & $0.83(0.92)$ & $0.83(0.92)$ & $-1.17(1.00)$ & $-1.17(1.00)$ \\
\hline
\end{tabular}

${ }^{a}$ The parametrization for $\phi_{\mathrm{cc}}-\langle\phi\rangle$, linked to equation (5), is a slope times $\sigma_{\phi} \operatorname{sign}(-\Delta \phi)$. The parametrization for $\phi_{\mathrm{cc}}-\bar{\phi}\left(z_{b}\right)$, linked to equation (6), is a slope times $\bar{\phi}\left(z_{b}\right)-\langle\phi\rangle$. These parametrizations are derived using the standard case (SC) and the Transparent Clouds (TC) case. Listed are the slopes with their corresponding indices of agreement in parentheses.

experiment during this hour. In Figure 8, the vertical transport of INERT, BLS, $\mathrm{C}_{5} \mathrm{H}_{8}$, and $\mathrm{O}_{3}$ is presented. The parametrized mass flux is plotted at the height of the hourly averaged $z_{b}$. Figure 8 confirms that the transport in the cloud cores makes up for the majority of the total vertical transport in the cloud layer, the two quantities being very similar in magnitude. Additionally, this figure shows that the organized (mass flux) transport is virtually equal to the total transport in the clouds, justifying the assumption that the turbulent transport in the clouds is negligible compared to the organized transport. Furthermore, the predicted vertical transport, using equation (3) and the parametrization of equation (13), agrees very well with the actual transport by $\mathrm{SCu}$ convection. This is especially the case for INERT (Figure 8a), BLS (Figure 8b), and isoprene (Figure 8c), while also the ozone flux (Figure 8d) is captured satisfactorily. For the simulation in which the UV radiation is not modified by clouds, TC, the match for ozone is similar to INERT, BLS, and isoprene (not shown).

[43] As mentioned in section 3.4, the aforementioned assumptions about vertical transport do not comply with all reactants. Here we analyze two interconnected atmospheric compounds in particular: $\mathrm{NO}$ and $\mathrm{NO}_{2}$. Similar to Figure 8, the vertical transport for $\mathrm{NO}$ and $\mathrm{NO}_{2}$ is presented in Figure 9 for both the SC and TC numerical experiments. For the standard case (Figures 9a and 9b), the vertical transport is again dominated by the transport in the cloud cores. However, the mass flux transport is not equal to the total transport in the cloud cores. As these differences do not occur for most atmospheric compounds in the model and since the differences for the short-lived $\mathrm{NO}$ and $\mathrm{NO}_{2}$ seem to cancel each other, this feature is most likely caused by the $\mathrm{NO} / \mathrm{NO}_{2}$ partitioning, which is influenced by the UV radiation modification below the $\mathrm{SCu}$ clouds. Due to the resulting lower photolysis rate in reaction $\mathrm{R} 5$ (see Table 1), the $\mathrm{NO} / \mathrm{NO}_{2}$ ratio is shifted to smaller values below the clouds [Vilà-Guerau de Arellano et al., 2005]. The time scale associated with the photostationary state equilibrium is in the order of minutes. Within the turbulent motions in the cloud cores, the higher vertical velocities are associated more with air that comes from below the cloud, while the lower vertical velocities are associated more with air from above. Due to the smaller $\mathrm{NO}$ and larger $\mathrm{NO}_{2}$ mixing ratios below the clouds, the turbulent motions in the cloud cores will have a negative contribution to the vertical flux of NO and a positive contribution to the vertical flux of $\mathrm{NO}_{2}$. This agrees with the results presented in Figures $9 a$ and $9 b$. The depicted vertical fluxes reflect as well that the parametrizations are not representative for $\mathrm{NO}$ and $\mathrm{NO}_{2}$ at the same level compared to the atmospheric compounds presented in Figure 8. For $\mathrm{NO}_{2}$ the parametrized mass flux transport is of the right order, albeit an underprediction. However, the predicted transport of NO is negligible compared to the actual transport calculated by DALES.

[44] As discussed above, the poor representation of the vertical transport of these short-lived chemical compounds is likely the result of the $\mathrm{NO} / \mathrm{NO}_{2}$ partitioning that depends on the local concentrations of other atmospheric compounds and UV radiation. To check whether this hypothesis is the full explanation, the flux of $\mathrm{NO}_{x}\left(\mathrm{NO}+\mathrm{NO}_{2}\right)$ is evaluated, since this generic species has a longer lifetime $(\sim 15 \mathrm{~h})$ and is less affected by UV radiation and concentrations of other atmospheric compounds. However, first the sole impact of the UV radiation modification by clouds on the vertical transport of $\mathrm{NO}$ and $\mathrm{NO}_{2}$ is further investigated by analyzing the TC numerical experiment. Figures $9 \mathrm{c}$ and $9 \mathrm{~d}$ show that the absence of UV radiation modification below the clouds results in altered vertical transport of $\mathrm{NO}$ and $\mathrm{NO}_{2}$ compared to the SC numerical experiment at all heights. Even though the subcloud layer averaged quantities of $\mathrm{NO}$ and $\mathrm{NO}_{2}$ are not influenced significantly by this local difference in UV radiation below the clouds, their horizontally averaged vertical fluxes are. The transport in the cloud cores is again of the same order as the total vertical transport, but in contrast 

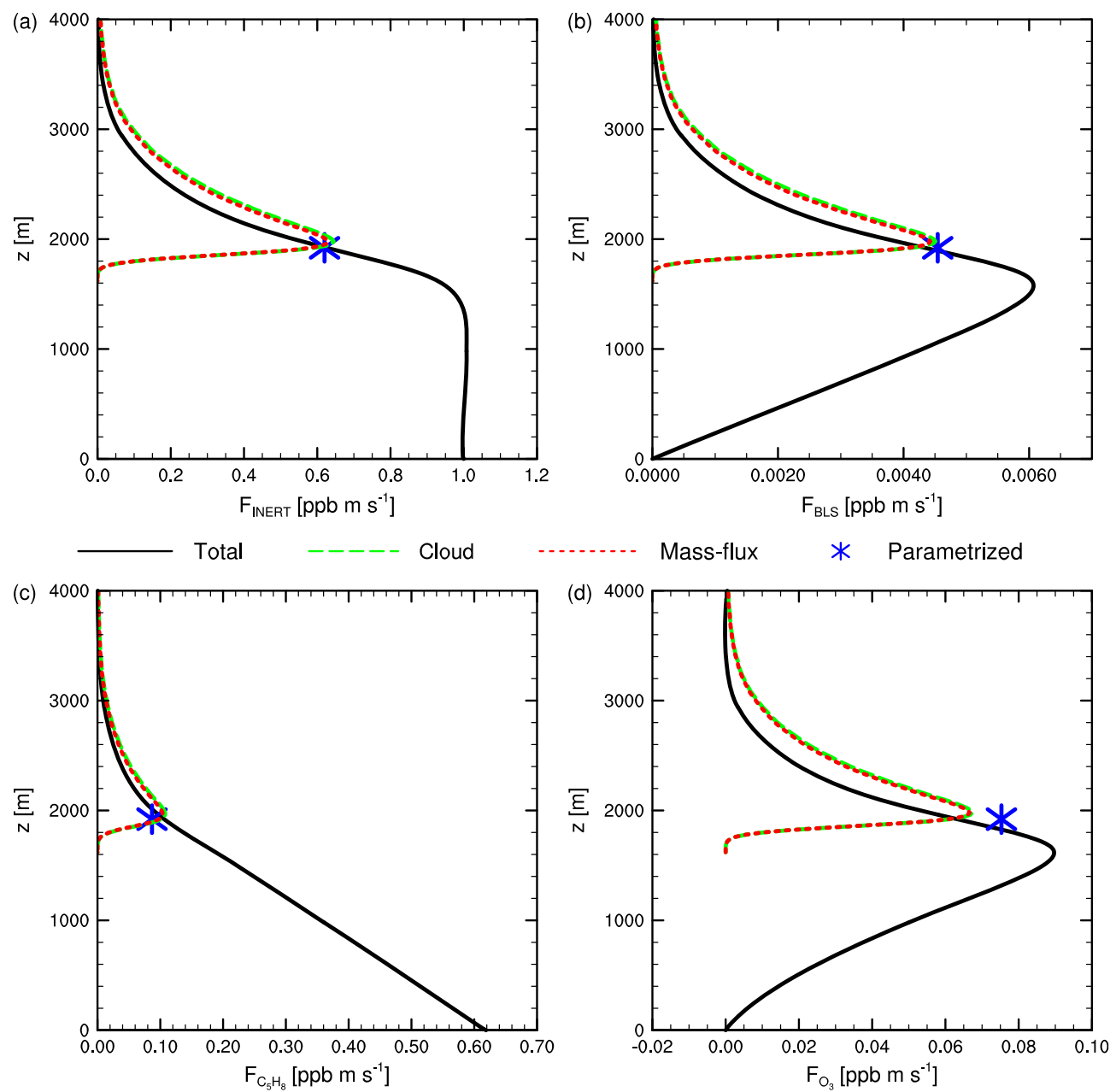

Figure 8. Vertical transport of the atmospheric compounds (a) INERT, (b) BLS, (c) $\mathrm{C}_{5} \mathrm{H}_{8}$, and (d) $\mathrm{O}_{3}$. The data is averaged between 1200 and 1300 LT. The black lines show the total vertical fluxes. The vertical transport in the cloud cores is depicted by the dashed green lines and the organized transport in the cloud cores through the mass flux by the red dashed lines. The blue asterisks represent the parametrized (mass flux) vertical transport using the diagnosed $M$ and the parametrization of equation (13) according to equation (3).

to Figures $9 \mathrm{a}$ and $9 \mathrm{~b}$, the turbulent flux of $\mathrm{NO}$ and $\mathrm{NO}_{2}$ in the cloud cores is in this numerical experiment negligible compared to the organized mass flux transport. Thus, the UV radiation modification explains part of the different behavior of the $\mathrm{NO}$ and $\mathrm{NO}_{2}$ transport compared to the transport of chemical species that are not very sensitive to the local and instantaneous UV radiation (e.g., INERT, BLS/FT, and isoprene). However, the parametrized transport still differs significantly from the vertical flux in the cloud cores that is calculated by DALES. The $\mathrm{NO}_{2}$ mass flux transport is overpredicted and again the predicted NO mass flux transport is negligible compared to the actual transport. To check whether these remaining differences are caused by temporary shifts in the $\mathrm{NO} / \mathrm{NO}_{2}$ partitioning related to the spatial distribution of other reactants, the vertical flux of $\mathrm{NO}_{x}$ is analyzed. Note that a similar analysis for $\mathrm{O}_{x}\left(\mathrm{O}_{3}+\mathrm{NO}_{2}\right)$ yields comparable results as for $\mathrm{O}_{3}$, due to the relatively low concentration of $\mathrm{NO}_{2}$.

[45] Figure 10 shows the vertical transport of $\mathrm{NO}_{x}$ for the SC numerical experiment. The actual and parametrized vertical transport (not shown) are almost identical for the
TC numerical experiment. These results confirm that $\mathrm{NO}_{x}$ behaves like the inert atmospheric compounds depicted in Figure 8 . The total vertical transport in the cloud layer is dominated by the vertical transport in the cloud cores. In turn, this latter transport is virtually equal to the organized mass flux transport. Finally, while the parametrization of the mass flux transport, using equations (3) and (13), did not result in accurate predictions for the individual $\mathrm{NO}$ and $\mathrm{NO}_{2}$ fluxes, the prediction for the $\mathrm{NO}_{x}$ flux matches the actual vertical transport very well. As an illustration, using solely $\mathrm{NO}_{x}$ to derive the constant in equation (13) would result in $-1.20(d=0.98)$ for the SC numerical experiment. This value is very similar to those derived for the inert tracers INERT and BLS/FTS (see Table 2).

\subsection{Heterogeneous Surface Forcings}

[46] The results presented in the previous sections strengthen confidence in the general applicability of the derived predictive expressions to represent the reactant transport from subcloud layer to cloud layer. Similar to the parametrizations for $q$, in general, the cloud core mixing 

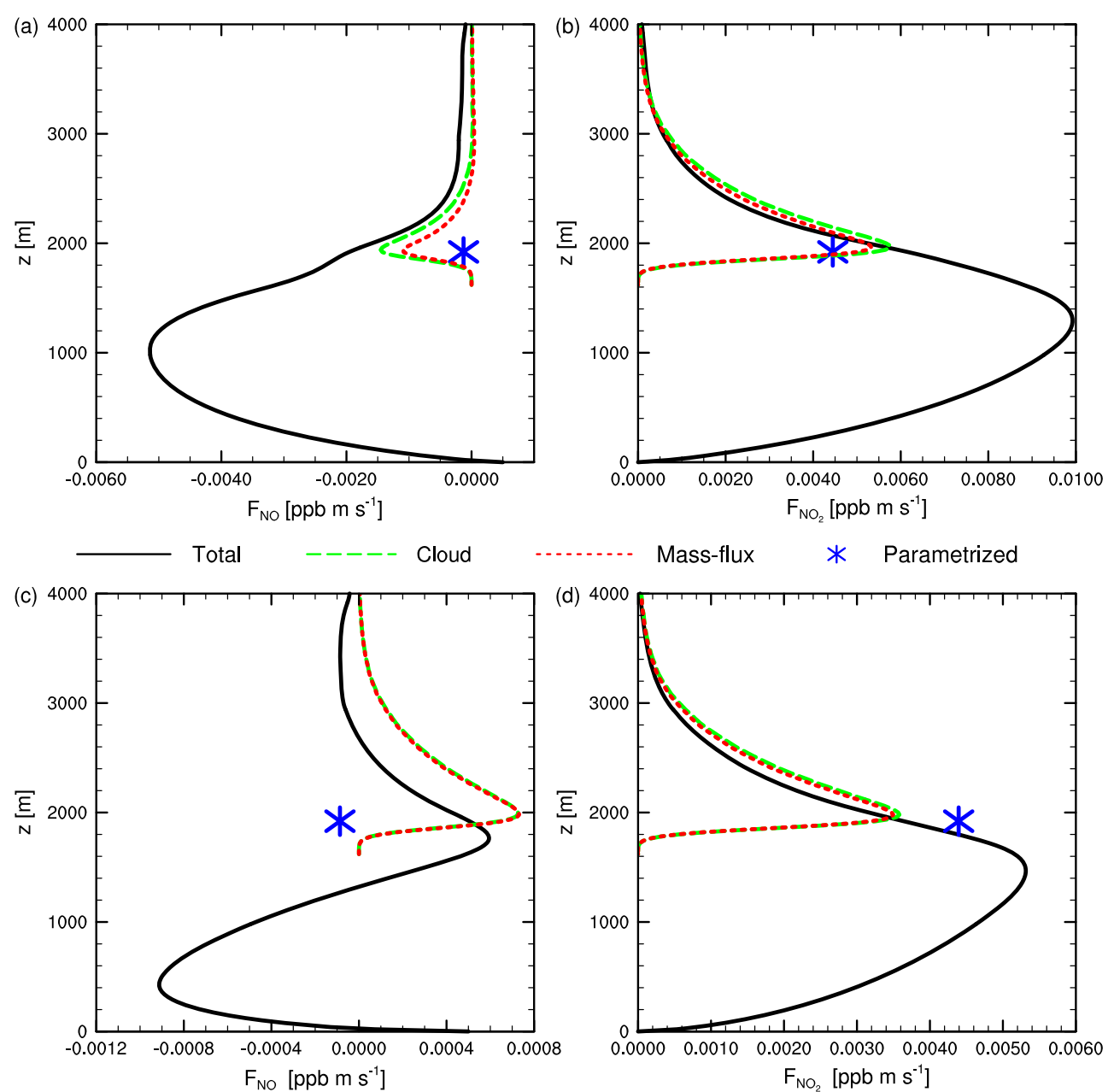

Figure 9. Vertical transport of the atmospheric compounds $(\mathrm{a}, \mathrm{c}) \mathrm{NO}$ and $(\mathrm{b}, \mathrm{d}) \mathrm{NO}_{2}$. The results are shown for the numerical experiments (Figures 9a and 9b) SC and (Figures 9c and 9d) TC. The data is averaged between 1200 and 1300 LT. The black lines show the total vertical fluxes. The vertical transport in the cloud cores is depicted by the dashed green lines and the organized transport in the cloud cores through the mass flux by the red dashed lines. The blue asterisks represent the parametrized (mass flux) vertical transport using the diagnosed $M$ and the parametrization of equation (13) according to equation (3).

ratios are shown to be accurately predicted by equations (12) and (13) in our numerical experiments. Next, we investigate whether the predictive expressions still hold if initial or boundary conditions are altered. We select a situation that can have a profound impact on the cloud characteristics and therefore on $\mathrm{SCu}$ convection: heterogeneous surface forcings, which induce secondary circulations [Patton et al., 2005; Ouwersloot et al., 2011]. This numerical experiment, which is described in section 2.3 , is referred to as the heterogeneous surface (HS) experiment.

[47] Due to the induced mesoscale circulations, the upward (downward) motions are located over the savannah (forest) patches. Emitted reactants are transported to the savannah patches and then upward, while entrained air is transported to the forest patches and then downward [Ouwersloot et al., 2011]. As a result, over the forest, the subcloud layer specific humidity and mixing ratios are more characterized by their values in the (entrained) free tropospheric air than over the savannah. Therefore, $q$ and the mixing ratios of, e.g., INERT, BLS, $\mathrm{NO}_{x}$, and $\mathrm{C}_{5} \mathrm{H}_{8}$ in the subcloud layer are all relatively high over savannah and low over forest (not shown). As the SCu clouds are formed at the top of thermals, they are now solely located over the savannah patches. This suggests that compared to the homogeneous SC numerical experiment, the properties of the air that escapes the subcloud layer deviate more from the properties of both the entrained air and the average subcloud layer air, resulting in constants with larger magnitudes in equations (8), (11), (12), and (13).

[48] It should be noted that over the savannah patches, the coverage and area fractions of clouds and cloud cores are enhanced such that, over the entire domain, their magnitudes are similar to the SC numerical experiment. However, their evolution is shifted forward by approximately half an hour. As a result, the mass flux is advanced by half an hour as well. Due to the stronger positive wind velocities over the savannah patches, related to the induced mesoscale circulations [Patton et al., 2005], $w$ in the cloud core becomes 


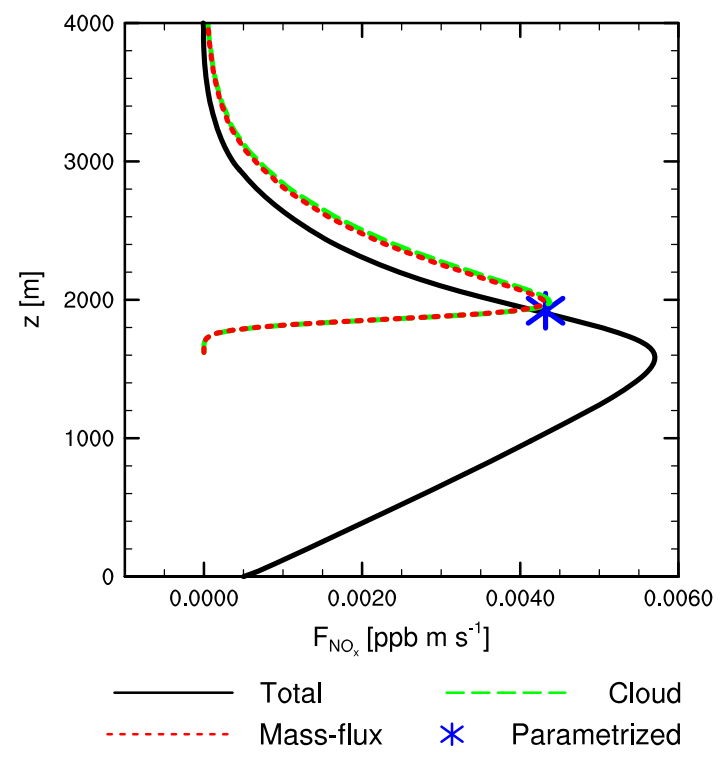

Figure 10. Vertical transport of $\mathrm{NO}_{x}$ for the $\mathrm{SC}$ numerical experiment. The data is averaged between 1200 and 1300 LT. The black line shows the total vertical flux. The vertical transport in the cloud cores is depicted by the dashed green line and the organized transport in the cloud cores through the mass flux by the red dashed line. The blue asterisk represents the parametrized (mass flux) vertical transport using the diagnosed $M$ and the parametrization of equation (13) according to equation (3).

higher (maximum difference is a $56 \%$ increase). As a result, the mass flux is enhanced as well, although the order remains similar.

[49] Compared to the SC numerical experiment, the mixed layer height never differs more than $118 \mathrm{~m}(7 \%)$ and its final value differs less than $10 \mathrm{~m}$. As a result, the convective velocity scale, $w_{*}$, deviates only insignificantly (maximum 2\%) compared to the SC numerical experiment, too. We find that the linear relation of equation (7) is still valid, however, related to the increased $w_{\mathrm{cc}}, \lambda=0.91$ (with $d=0.93$ ), which is significantly different from 0.84 . Additionally, we find that for the HS data, in order to accurately predict $q_{\mathrm{cc}}-<q>, \zeta$ in equation (8) should be 0.63 (with $d=0.65$ ) rather than the previously determined 0.51 by B. J. H. van Stratum et al. (submitted manuscript, 2013) or 0.53 for the $\mathrm{SC}$ numerical experiment. In the alternative equation (11), $\zeta_{2}$ becomes 1.06 instead of 1.01. These results underscore that, even though $q_{\mathrm{cc}}$ and $w_{\mathrm{cc}}$ can still be parametrized using the previously applied linear functions, the proportionality factors in these expressions depend on the boundary conditions of the evaluated ABL. The constants for the SC and HS numerical experiments are listed in Table 3. Future studies are recommended to address how the constants $\lambda, \zeta$, and $\zeta_{2}$ depend on the initial and boundary conditions.

[50] Here we evaluate the vertical transport of atmospheric reactants. Figure 11 shows the dependencies of equation (13) for INERT, BLS, isoprene, and CO in the HS numerical experiment, using an updated value for $\xi_{2}$. The data points match the regression line well, indicating that the aforementioned equations still adequately represent the mixing ratios in the active clouds if the constant $\xi_{2}$ is adapted.
Table 3. The Proportionality Factors $\lambda, \zeta, \zeta_{2}, \xi$, and $\xi_{2}$ of Equations (7), (8), (11), (12), and (13) as Derived in Section 3.6 for the Standard Case (SC) and the Numerical Experiment With Heterogeneous Surface Conditions (HS)

\begin{tabular}{lcc}
\hline Factor & $\mathrm{SC}$ & $\mathrm{HS}$ \\
\hline$\lambda$ & 0.84 & 0.91 \\
$\zeta$ & 0.53 & 0.63 \\
$\zeta_{2}$ & 1.01 & 1.06 \\
$\xi$ & 0.91 & 0.99 \\
$\xi_{2}$ & -1.23 & -1.42 \\
\hline
\end{tabular}

For these four chemical species combined, $\xi_{2}$ changes from -1.23 to -1.42 . Evaluating all chemical species together (not shown) results in $\xi=0.99$ instead of 0.91 (in equation (12)) and $\xi_{2}=-1.42$ instead of -1.23 . As was the case for specific humidity, the mixing ratios in the cloud cores can thus be predicted using the previously applied linear relations if the change in slopes for equations (12) and (13) are taken into account.

[51] Similar to Figure 8, the vertical transport of INERT, BLS, isoprene, and ozone is depicted in Figure 12 for the HS numerical experiment. The parametrized mass flux is calculated using the updated equation (12) with $\xi_{2}=-1.42$. The organized mass flux transport is still the dominant contribution to the total vertical transport in the cloud cores for all tracers. For INERT, BLS, and isoprene, this transport is a satisfactory match to the total vertical flux in the cloud layer. For ozone, on the other hand, the total vertical flux significantly deviates from the transport in the cloud cores. This could be caused by transport in the cloud shells, as hypothesized by Heus and Jonker [2008] and Jonker et al. [2008]. In the cloud shells, on average the air descends.

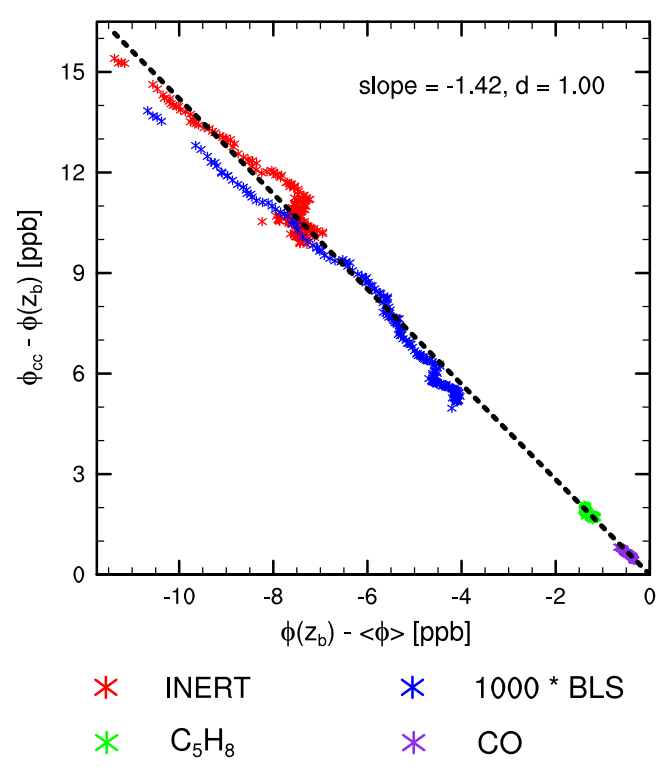

Figure 11. Parametrization for $\phi_{\mathrm{cc}}-\bar{\phi}\left(z_{b}\right)$ (related to equation (6)) as a function of $\bar{\phi}\left(z_{b}\right)-\langle\phi\rangle$. Here the numerical experiment with heterogeneous surface forcings is evaluated. The values for $\phi$ represent the mixing ratios of INERT, BLS, $\mathrm{C}_{5} \mathrm{H}_{8}$, and $\mathrm{CO}$. The black dashed line indicates the linear regression fit through all (unscaled) data, forced through $(0,0)$. The asterisks are data sampled at $1 \mathrm{~min}$ intervals. The slope and index of agreement, $d$, are indicated. 

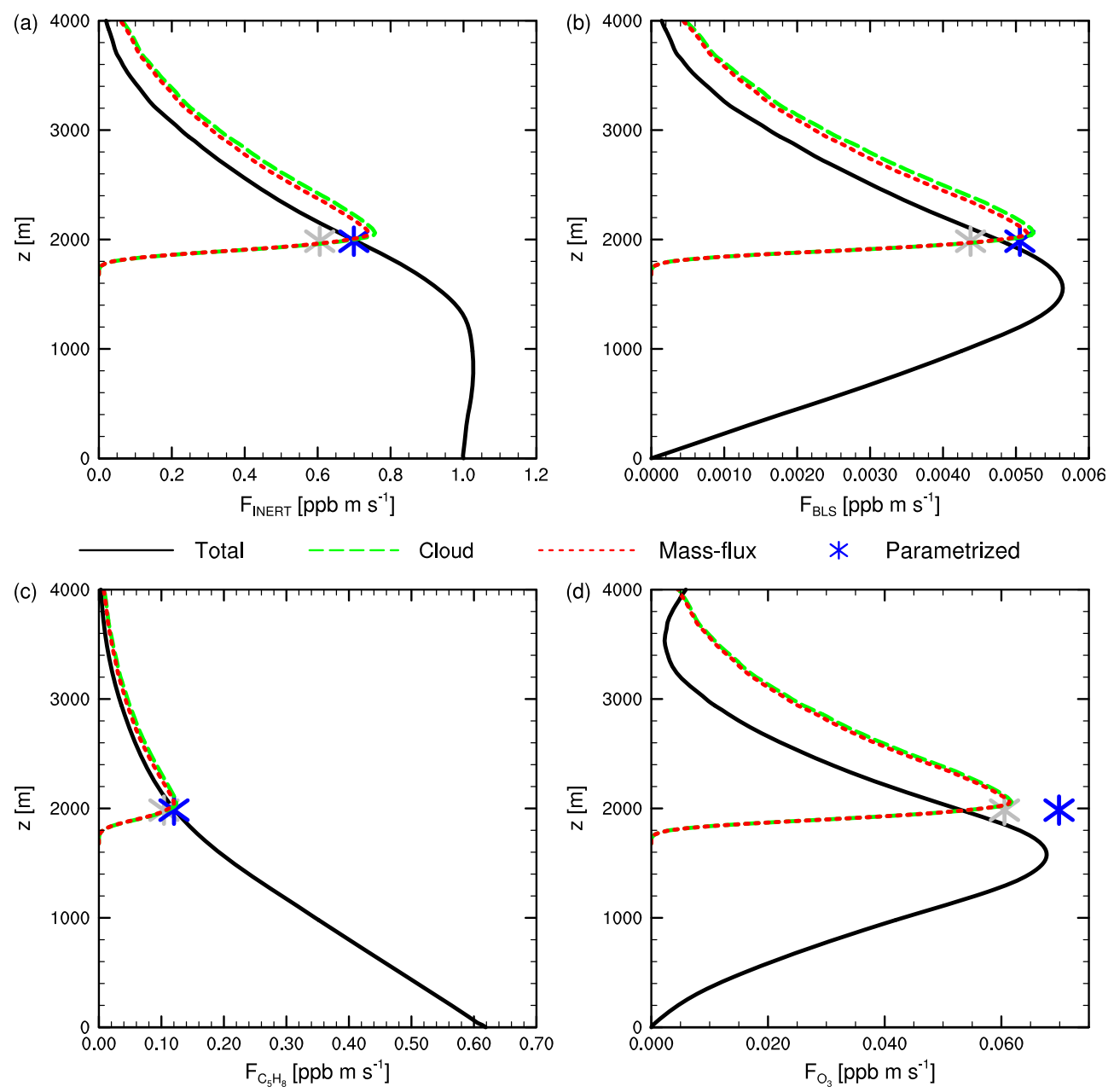

Figure 12. Vertical transport of atmospheric compounds (a) INERT, (b) BLS, (c) $\mathrm{C}_{5} \mathrm{H}_{8}$, and (d) $\mathrm{O}_{3}$ for the numerical experiment with heterogeneous surface forcings. The data are averaged between 1200 and 1300 LT. The black lines show the total vertical fluxes. The vertical transport in the cloud cores is depicted by the dashed green lines and the organized transport in the cloud cores through the mass flux by the red dashed lines. The blue asterisks represent the parametrized (mass flux) vertical transport using the diagnosed $M$ and the parametrization of equation (13) with $\xi_{2}=-1.42$ according to equation (3). The grey asterisks represent the parametrized vertical transport using the original $\xi_{2}=-1.23$.

As the shells are positioned between the cloud cores and the environment and partly return air downward after it was transported upward in the cores, they are most likely to reduce the effect of the cloud core transport. For the heterogeneous case, the clouds are concentrated over the savannah patches. Since the clouds, and the thermals they are rooted into, are concentrated over a smaller domain, the clouds become more active. These clouds grow deeper (reaching a maximum horizontally averaged thickness of $1900 \mathrm{~m}$ instead of $1400 \mathrm{~m}$ ) and the transport by cloud shells increases. As mentioned in section 2.1.1, to evaluate why $\mathrm{O}_{3}$ is affected more than the other chemical species, an analysis could be performed in which the transport is partitioned in advective and turbulent fluxes in three areas: cloud core, cloud shell, and environment. However, as this section only aims at checking whether the concept of mass flux transport and its parametrizations hold for all conditions, this is beyond the scope of this study. Finally, the predicted vertical transport, using equations (3) and (13) with $\xi_{2}=-1.42$, agrees well with the actual transport by $\mathrm{SCu}$ convection.
[52] Although our analysis is not a comprehensive sensitivity study, it is clearly demonstrated that, even though the factors in the parametrizations were approximately equal between the $\mathrm{SC}$ numerical experiment presented in this study and the three numerical experiments presented by B. J. H. van Stratum et al. (submitted manuscript, 2013), changing the applied boundary conditions can result in changes in the parameters of the expressions that predict the mass flux and the resulting transport of humidity and atmospheric reactants. Thus, it is demonstrated that heterogeneous surface forcings can affect the prognostic expressions and future research will have to show in more detail which initial and boundary conditions affect the parametrizations and how the proportionality factors $\left(\lambda, \zeta, \zeta_{2}, \xi, \xi_{2}\right)$ in the various equations (equations (7), (8), (11), (12) and (13)) are affected by these conditions. The altered constants that are presented in this section are therefore not typical for every situation with heterogeneous surface conditions, but demonstrate the need to be cautious in applying the standard parametrization equations with factors that are derived for particular 
conditions. Note that even though the constants in the predictive expressions are affected by surface heterogeneity, the magnitude is still the same and the dependencies are still well represented by linear functions. Therefore, if a numerical model does not explicitly resolve transport by $\mathrm{SCu}$ convection, applying the parametrizations with the constants of the SC numerical experiment is still an improvement compared to not applying the parametrizations at all.

\section{Conclusions}

[53] We studied how mass flux transport by shallow cumulus convection, which is driven by fair weather clouds that form over the Amazon region, affects subcloud layer atmospheric reactants by analyzing large eddy simulation data. These Amazonian conditions are based on observations in the TROFFEE campaign. For the analysis of the numerical data, two different expressions for the budget of the mixing ratio evolutions in the diurnal atmospheric boundary layer are derived using mixed layer theory. These expressions are equivalent, though correspond to different physical interpretations. Between these two budget expressions, it is found that in the expression relevant for chemistry transport models (the pumping budget) the mass flux transport contributes more significantly to reactant mixing ratio evolutions. This influence on the subcloud layer reactant mixing ratios is for most chemical species relatively small, being of the order of a few percent per hour. However, for some reactants, the contribution of the mass flux transport to the mixing ratio evolution is more significant. For example, during shallow cumulus convection, isoprene decreases on average by $8.5 \%$ per hour and at maximum (when the shallow cumulus clouds are fully developed) by $15 \%$ per hour due to the mass flux transport. As the influence of mass flux transport is significant for some atmospheric reactants, it is recommended that this subgrid process is taken into account in chemistry transport and climate models.

[54] To represent this transport in these models, we first evaluated the parametrizations for the dynamical variables (vertical wind and specific humidity) that were previously derived for three independent numerical LES experiments. The results corroborate that the proposed linear expressions for the parametrizations and their constants are valid over a wide range of conditions. Additionally, our LES data indicate that the specific humidity in the cloud cores is better predicted by the total (volumetric) standard deviation of moisture in the subcloud layer than by the horizontal standard deviation near the top of this layer. It is therefore recommended to investigate in future studies whether this is also the case for other conditions with active shallow cumulus convection. Second, the representations for the cloud core values were investigated. Assuming linear dependencies, we determined to which variables these representations scale best and with which proportionality factors. The derived linear expressions to predict the mixing ratios in the cloud cores compare well with LES data for many reactants, but not for all. The latter is especially the case for reactants whose concentrations are highly dependent on the local and instantaneous UV radiation. Due to the modification of the UV radiation distribution by the clouds, the chemical equilibrium between some species, such as NO and $\mathrm{NO}_{2}$, is perturbed. It is demonstrated by an additional LES experiment that if UV radiation modification by clouds is not applied, also, these reactants comply with the standard linear expressions. Since these UV dependent reactants are restored to their original equilibria in the regions where the UV radiation is not modified by the clouds, the standard parametrizations adequately represent the transport of reactants from the subcloud layer to the cloud layer by shallow cumulus convection.

[55] It is shown that in general, in the cloud layer, the vertical transport of atmospheric reactants is governed by organized shallow cumulus convection. In turn, this mass flux transport is accurately predicted by the derived expressions. However, there are a few, but relevant exceptions, particularly $\mathrm{NO}$ and $\mathrm{NO}_{2}$. By analyzing the mass flux transport of the generic species $\mathrm{NO}_{x}$, it is shown that this is caused by departures from the chemical equilibrium that are linked to local concentrations of other atmospheric compounds, such as ozone. For $\mathrm{NO}_{x}$, the mass flux transport matches the total vertical flux very well and the parametrizations agree satisfactorily with the LES model. As the $\mathrm{NO} / \mathrm{NO}_{2}$ partitioning is locally determined, predicting the $\mathrm{NO}_{x}$ transport accurately, suffices for numerical models that aim to represent $\mathrm{NO}$ and $\mathrm{NO}_{2}$.

[56] Finally, the robustness of the parametrizations has been explored. For conditions with heterogeneous surface forcings, it is shown that, while the prognostic expressions still have the same linear dependencies as previously determined, the proportionality factors in all expressions have to be enhanced to make them agree with the LES experiment over heterogeneous terrain. This shows that the derived parametrizations for the mass flux and corresponding transport of subcloud layer reactants are dependent on boundary conditions, including heterogeneous surface forcings. Further research is needed to investigate on which other conditions they depend and how these dependencies can be explicitly incorporated in the parametrizations. It should also be noted that the diagnosed constants in the various predictive expressions remain of similar magnitude for the different evaluated conditions. Therefore, until the sensitivities to the different boundary and initial conditions are identified, chemistry transport and climate models would already benefit from applying the diagnosed expressions.

[57] Acknowledgments. H.O. gratefully acknowledges financial support by the Max Planck Society for this project. The modeling part of this study was sponsored by the National Computing Facilities Foundation (NCF project SH-060-13) for the use of supercomputer facilities. M.K. is supported by the EU FP7 IP PEGASOS (FP7-ENV-2010/265148)

\section{References}

Angevine, W. M., H. Jiang, and T. Mauritsen (2010), Performance of an eddy diffusivity-mass flux scheme for shallow cumulus boundary layers, Mon. Wea. Rev, 138, 2895-2912, doi:10.1175/2010MWR3142.1.

Brown, A. R., et al. (2002), Large-eddy simulation of the diurnal cycle of shallow cumulus convection over land, Q. J. Roy. Meteor. Soc., 128, 1075-1093, doi:10.1256/003590002320373210.

Butler, T. M., D. Taraborrelli, C. Brühl, H. Fischer, H. Harder, M. Martinez, J. Williams, M. G. Lawrence, and J. Lelieveld (2008), Improved simulation of isoprene oxidation chemistry with the ECHAM5/MESSy chemistry-climate model: Lessons from the GABRIEL airborne field campaign, Atmos. Chem. Phys., 8, 4529-4546, doi:10.5194/acp-8-45292008.

Cuijpers, J. W. M., and P. G. Duynkerke (1993), Large eddy simulation of trade wind cumulus clouds, J. Atmos. Sci., 50, 3894-3908, doi:10.1175/1520-0469(1993)050<3894:LESOTW>2.0.CO;2. 


\section{OUWERSLOOT ET AL.: SHALLOW CUMULUS TRANSPORT OF REACTANTS}

da Rocha, H. R., et al. (2009), Patterns of water and heat flux across a biome gradient from tropical forest to savanna in Brazil, J. Geophys. Res., 114, G00B12, doi:10.1029/2007JG000640.

Deardorff, J. W. (1973), Three-dimensional numerical modeling of the planetary boundary layer, in Workshop on Meteorology, edited by D. A. Haugen, pp. 271-311, Amer. Meteorol. Soc., Boston, USA.

Doran, J. C., W. J. Shaw, and J. M. Hubbe (1995), Boundary layer characteristics over areas of inhomogeneous surface fluxes, J. Appl. Meteor., 34, 559-571, doi:10.1175/1520-0450-34.2.559.

Dosio, A., J. Vilà-Guerau de Arellano, A. M. Holtslag, and P. J. H. Builtjes (2003), Dispersion of a passive tracer in buoyancy- and shear-driven boundary layers, J. Appl. Meteor., 42, 1116-1130, doi:10.1175/15200450(2003)042<1116:DOAPTI>2.0.CO;2.

Ganzeveld, L., et al. (2008), Surface and boundary layer exchanges of volatile organic compounds, nitrogen oxides and ozone during the gabriel campaign, Atmos. Chem. Phys., 8, 6223-6243, doi:10.5194/acp-8-62232008.

Gentine, P., A. K. Betts, B. R. Lintner, K. L. Findell, C. C. van Heerwaarden, and F. D'Andrea (2013), A probabilistic bulk model of coupled mixed layer and convection. Part II: Shallow convection case, $J$. Atmos. Sci., 70, 1557-1576, doi:10.1175/JAS-D-12-0146.1.

Hahn, C. J., and S. G. Warren (2007), A Gridded Climatology of Clouds Over Land (1971-96) and Ocean (1954-97) From Surface Observations Worldwide. Numeric Data Package NDP-026E, CDIAC, Department of Energy, Oak Ridge, Tennessee, doi:10.3334/CDIAC/cli.ndp026e.

Heus, T., and H. J. J. Jonker (2008), Subsiding shells around shallow cumulus clouds, J. Atmos. Sci., 65, 1003-1018, doi:10.1175/2007JAS2322.1.

Heus, T., et al. (2010), Formulation of the Dutch Atmospheric Large-Eddy Simulation (DALES) and overview of its applications, Geosci. Model Dev., 3, 415-444, doi:10.5194/gmd-3-415-2010.

Jonker, H. J. J., T. Heus, and P. P. Sullivan (2008), A refined view of vertical mass transport by cumulus convection, Geophys. Res. Lett., 35, L07810, doi:10.1029/2007GL032606.

Karl, T., A. Guenther, R. Yokelson, J. Greenberg, M. Potosnak, D. R. Blake, and P. Artaxo (2007), The tropical forest and fire emissions experiment: Emission, chemistry, and transport of biogenic volatile organic compounds in the lower atmosphere over amazonia, J. Geophys. Res., 112, D18302, doi:10.1029/2007JD008539.

Kim, S.-W., M. C. Barth, and M. Trainer (2012), Influence of fair-weather cumulus clouds on isoprene chemistry, J. Geophys. Res., 117, D10302, doi:10.1029/2011JD017099.

Lelieveld, J., T. M. Butler, J. N. Crowley, T. J. Dillon, H. Fischer, L. Ganzeveld, H. Harder, M. G. Lawrence, M. Martinez, D. Taraborrelli, and J. Williams (2008), Atmospheric oxidation capacity sustained by a tropical forest, Nature, 452, 737-740, doi:10.1038/nature06870.

LeMone, M. A., and W. T. Pennell (1976), The relationship of trade wind cumulus distribution to subcloud layer fluxes and structure, Mon. Wea. Rev., 104, 524-539, doi:10.1175/1520-0493(1976)104<0524: TROTWC $>2.0 . \mathrm{CO} ; 2$.

Lilly, D. K. (1968), Models of cloud-topped mixed-layer under a strong inversion, Q. J. Roy. Meteor. Soc., 94, 292-309, doi:10.1002/qj. 49709440106

Madronich, S. (1987), Photodissociation in the atmosphere: 1. Actinic flux and the effects of ground reflections and clouds, J. Geophys. Res., 92 9740-9752, doi:10.1029/JD092iD08p09740.

Neggers, R., B. Stevens, and J. D. Neelin (2006), A simple equilibrium model for shallow-cumulus-topped mixed layers, Theor. Comput. Fluid. Dyn., 20, 305-322, doi:10.1007/s00162-006-0030-1.

Neggers, R. A. J., P. G. Duynkerke, and S. M. A. Rodts (2003), Shallow cumulus convection: A validation of large-eddy simulation against aircraft and landsat observations, Q. J. Roy. Meteor. Soc., 129, 2671-2696, doi:10.1256/qj.02.93.

Neggers, R. A. J., B. Stevens, and J. D. Neelin (2007), Variance scaling in shallow-cumulus-topped mixed layers, Q. J. Roy. Meteor. Soc., 133, 1629-1641, doi:10.1002/qj.105.

Nieuwstadt, F. T. M., and R. A. Brost (1986), The decay of convective turbulence, J. Atmos. Sci., 43, 532-545, doi:10.1175/15200469(1986)043<0532:TDOCT>2.0.CO;2.
Ouwersloot, H. G., J. Vilà-Guerau de Arellano, C. C. van Heerwaarden, L. N. Ganzeveld, M. C. Krol, and J. Lelieveld (2011), On the segregation of chemical species in a clear boundary layer over heterogeneous land surfaces, Atmos. Chem. Phys., 11, 10,681-10,704, doi:10.5194/acp-1110681-2011.

Ouwersloot, H. G., J. Vilà-Guerau de Arellano, A. C. Nölscher, M. C. Krol, L. N. Ganzeveld, C. Breitenberger, I. Mammarella, J. Williams, and J. Lelieveld (2012), Characterization of a boreal convective boundary layer and its impact on atmospheric chemistry during HUMPPA-COPEC2010, Atmos. Chem. Phys., 12, 9335-9353, doi:10.5194/acp-12-93352012.

Patton, E. G., P. P. Sullivan, and C.-H. Moeng (2005), The influence of idealized heterogeneity on wet and dry planetary boundary layers coupled to the land surface, J. Atmos. Sci., 62, 2078-2097, doi:10.1175/JAS3465.1.

Roelofs, G.-J., and V. Kamphuis (2009), Cloud processing, cloud evaporation and Angström exponent, Atmos. Chem. Phys., 9, 71-80, doi:10.5194/acp-9-71-2009.

Shrivastava, M., L. K. Berg, J. Fast, R. Easter, A. Laskin, E. Chapman, W. I. Gustafson Jr., Y. Liu, and C. Berkowitz (2013), Modeling aerosols and their interactions with shallow cumuli during the 2007 CHAPS field study, J. Geophys. Res. Atmos., 118, 1343-1360, doi:10.1029/2012JD018218.

Siebesma, A. P., and J. W. Cuijpers (1995), Evaluation of parametric assumptions for shallow cumulus convection, J. Atmos. Sci., 52, 650-666, doi:10.1175/1520-0469(1995)052<0650:EOPAFS $>2.0$. CO;2.

Sorooshian, A., N. L. Ng, A. W. H. Chan, G. Feingold, R. C. Flagan, and J. H. Seinfeld (2007), Particulate organic acids and overall water-soluble aerosol composition measurements from the 2006 Gulf of Mexico Atmospheric Composition and Climate Study (GoMACCS), J. Geophys. Res. 112, D13201, doi:10.1029/2007JD008537.

Stull, R. B. (1988), An Introduction to Boundary Layer Meteorology, 666 pp., Kluwer Academic Publishers, Dordrecht, The Netherlands.

van Heerwaarden, C. C., J. Vilà-Guerau de Arellano, A. Gounou, F. Guichard, and F. Couvreux (2010), Understanding the daily cycle of evapotranspiration: A method to quantify the influence of forcings and feedbacks, J. Hydrometeor., 11, 1405-1422, doi:10.1175/ 2010JHM1272.1.

van Stratum, B. J. H., et al. (2012), Case study of the diurnal variability of chemically active species with respect to boundary layer dynamics during DOMINO, Atmos. Chem. Phys., 12, 5329-5341, doi:10.5194/acp12-5329-2012.

Vilà-Guerau de Arellano, J., S.-W. Kim, M. C. Barth, and E. G. Patton (2005), Transport and chemical transformations influenced by shallow cumulus over land, Atmos. Chem. Phys., 5, 3219-3231, doi:10.5194/acp5-3219-2005.

Vilà-Guerau de Arellano, J., K. van den Dries, and D. Pino (2009), On inferring isoprene emission surface flux from atmospheric boundary layer concentration measurements, Atmos. Chem. Phys., 9, 3629-3640, doi:10.5194/acp-9-3629-2009.

Vilà-Guerau de Arellano, J., E. G. Patton, T. Karl, K. van den Dries, M. C. Barth, and J. J. Orlando (2011), The role of boundary layer dynamics on the diurnal evolution of isoprene and the hydroxyl radical over tropical forests, J. Geophys. Res., 116, D07304, doi:10.1029/2010JD014857.

Willmott, C. J. (1981), On the validation of models, Phys. Geogr., 2, 184-194.

Wyngaard, J. C., and R. A. Brost (1984), Top-down and bottom-up diffusion of a scalar in the convective boundary layer, J. Atmos. Sci., 41, 102-112, doi:10.1175/1520-0469(1984)041<0102:TDABUD>2.0.CO;2.

Zhang, Y., and S. A. Klein (2010), Mechanisms affecting the transition from shallow to deep convection over land: Inferences from observations of the diurnal cycle collected at the ARM southern great plains site, $J$. Atmos. Sci., 67, 2943-2959, doi:10.1175/2010JAS3366.1.

Zimmerman, P. R., J. P. Greenberg, and C. E. Westberg (1988), Measurement of atmospheric hydrocarbons and biogenic emission fluxes in the amazon boundary layer, J. Geophys. Res., 93, 1407-1416, doi:10.1029/JD093iD02p01407. 